Article

\title{
Improved Sample Selection and Preparation Methods for Sampling Plans Used to Facilitate Rapid and Reliable Estimation of Aflatoxin in Chicken Feed
}

\author{
James Kibugu ${ }^{1,2, *}$, Raymond Mdachi ${ }^{1}$, Leonard Munga ${ }^{3}{ }^{-}$, David Mburu ${ }^{2}{ }^{(0}$, Thomas Whitaker ${ }^{4}$, Thu P. Huynh ${ }^{5}$, \\ Delia Grace ${ }^{6}$ and Johanna F. Lindahl ${ }^{6,7,8(\mathbb{D})}$
}

1 Biotechnology Research Institute, Kenya Agricultural and Livestock Research Organization, P.O. Box 362, Kikuyu 00902, Kenya; rayelliemdachi@gmail.com

2 Department of Biochemistry, Microbiology and Biotechnology, School of Pure and Applied Sciences, Kenyatta University, P.O. Box 43844, Nairobi 00100, Kenya; nmburu01@gmail.com

3 Department of Animal Science, School of Agriculture and Enterprise Development, Kenyatta University, P.O. Box 43844, Nairobi 00100, Kenya; munga.leonard@ku.ac.ke

4 Department of Biological and Agricultural Engineering, North Carolina State University, Box 7625, Raleigh, NC 27695-7625, USA; whitaker@ncsu.edu

5 Hygiena LLC, Santa Ana, CA 92704-6804, USA; thuynh@hygiena.com

6 Department of Biosciences, International Livestock Research Institute, P.O. Box 30709, Nairobi 00100, Kenya; D.Randolph@cgiar.org (D.G.); J.Lindahl@cgiar.org (J.F.L.)

7 Department of Clinical Sciences, Swedish University of Agricultural Sciences, 75007 Uppsala, Sweden

8 Department of Medical Biochemistry and Microbiology, Uppsala University, 75123 Uppsala, Sweden

* Correspondence: jkkibugu1@yahoo.com

Citation: Kibugu, J.; Mdachi, R.; Munga, L.; Mburu, D.; Whitaker, T.; Huynh, T.P.; Grace, D.; Lindahl, J.F. Improved Sample Selection and Preparation Methods for Sampling Plans Used to Facilitate Rapid and Reliable Estimation of Aflatoxin in Chicken Feed. Toxins 2021, 13, 216. https://doi.org/10.3390/ toxins13030216

Received: 15 January 2021

Accepted: 10 March 2021

Published: 16 March 2021

Publisher's Note: MDPI stays neutral with regard to jurisdictional claims in published maps and institutional affiliations.

\section{Copyright: (c) 2021 by the authors.} Licensee MDPI, Basel, Switzerland. This article is an open access article distributed under the terms and conditions of the Creative Commons Attribution (CC BY) license (https:/ / creativecommons.org/licenses/by/ $4.0 /)$.

\begin{abstract}
Aflatoxin B1 (AFB1), a toxic fungal metabolite associated with human and animal diseases, is a natural contaminant encountered in agricultural commodities, food and feed. Heterogeneity of AFB1 makes risk estimation a challenge. To overcome this, novel sample selection, preparation and extraction steps were designed for representative sampling of chicken feed. Accuracy, precision, limits of detection and quantification, linearity, robustness and ruggedness were used as performance criteria to validate this modification and Horwitz function for evaluating precision. A modified sampling protocol that ensured representativeness is documented, including sample selection, sampling tools, random procedures, minimum size of field-collected aggregate samples (primary sampling), procedures for mass reduction to $2 \mathrm{~kg}$ laboratory (secondary sampling), $25 \mathrm{~g}$ test portion (tertiary sampling) and $1.3 \mathrm{~g}$ analytical samples (quaternary sampling). The improved coning and quartering procedure described herein (for secondary and tertiary sampling) has acceptable precision, with a Horwitz ratio (HorRat $=0.3$ ) suitable for splitting of $25 \mathrm{~g}$ feed aliquots from laboratory samples (tertiary sampling). The water slurring innovation (quaternary sampling) increased aflatoxin extraction efficiency to $95.1 \%$ through reduction of both bias (-4.95) and variability of recovery (1.2-1.4) and improved both intra-laboratory precision (HorRat $=1.2-1.5)$ and within-laboratory reproducibility (HorRat $=0.9-1.3$ ). Optimal extraction conditions are documented. The improved procedure showed satisfactory performance, good field applicability and reduced sample analysis turnaround time.
\end{abstract}

Keywords: aflatoxin; chicken feed; representative sampling; improved aflatoxin test procedure; validation

Key Contribution: This paper reports optimization and validation of processes employed to estimate aflatoxin levels in chicken feed. Modification of critical steps in sample collection and preparation segments of the aflatoxin test procedure enhanced the sampling representativeness necessary for rapid and accurate detection and estimation of dietary aflatoxin hazards. 


\section{Introduction}

Aflatoxins are food-borne toxins produced by Aspergillus fungi sections Flavi, Ochraceorosei and Nidulantes. Some aflatoxin producing species are A. flavus, A. parasiticus, A. nomius, $A$. minisclerotigenes and $A$. arachidicola whose aflatoxigenic strains are widespread in agricultural commodities, food and feed [1,2]. There are four types designated as aflatoxin B1, B2, G1 and G2 [3], found as natural dietary contaminants [4,5]. Metabolites such as aflatoxin $\mathrm{M}$ are found in edible animal products [5]. Aflatoxin B1 (AFB1), the most toxic and prevalent [2], is a potent human carcinogen [6]. Aflatoxins are moderately stable under normal cooking and industrial processing procedures $[4,7,8]$. There have been reports of acute human and animal aflatoxicosis outbreaks resulting in deaths $[9,10]$ and widespread exposure to chronic dietary aflatoxins $[2,11]$. Prevalence data of aflatoxins contamination in poultry feeds are scanty particularly in low- and middle-income countries and characterized by wide variation. Levels of $36 \mathrm{ppb}$ (mean) aflatoxin B1 was observed in Sudan [12], $100 \mathrm{ppb}$ (mean) in India [13], 10-166 ppb aflatoxin in Pakistan [14], $74 \mathrm{ppb}$ (mean) in Nigeria [15], 2.7 ppb (median) in Argentina [16] and 20-50 ppb in Kenya [17]. Recently, aflatoxin levels of 7.5-393.5 ppb in feed processing plants samples and 19.0-188.5 ppb in samples collected from farmers in Uganda [18] and 0.2-318 ppb in 2020 in Kenya were reported [19]. Maximum allowable limits for aflatoxin content in human food and animal feed have been established in more than 100 countries [20]. For total aflatoxins, the United States set a maximum guidance level of 20-300 ppb in animal feed and $20 \mathrm{ppb}$ in human food [21], while it is 4 ppb in human food as set by the European Union (EU) [22]. Other than for dairy feed, AFB1 residues in animal feed are not usually regulated [20]. Uniquely, however, the EU has established a threshold for this mycotoxin in several animal feed matrices [23].

Chronic aflatoxicosis aggravates disease pathogenesis, impairs animal nutrition and productivity $[6,24,25]$. Aflatoxins are also teratogenic, carcinogenic, mutagenic, estrogenic, nephrotoxic, hepatotoxic and immunosuppressive [2,6,26-28]. Aflatoxins promote development of human primary hepatocellular carcinoma through synergy with the hepatitis B virus and has been associated with childhood stunting [29]. In chicken, dietary aflatoxins decrease feed intake and productivity and impair reproduction, causing economic losses, increased susceptibility to disease, poor vaccine response and toxin residues in poultry products $[4,11,30]$. In fact, dietary aflatoxin can reduce weight gain by $11 \%$ and increase mortality by $2.8 \%$ in chicken [31]. Aflatoxin contamination also causes food insecurity and economic impact through its adverse effect on international trade [8]. Dietary aflatoxin is therefore a public health concern of paramount importance that requires accurate estimation to enable employment of appropriate intervention strategies. Substantial efforts have been made to improve sensitivity and throughput of the analytical methods used for estimation of aflatoxin in food and feed. Thus, great achievements have been accomplished in the improvement of the analytical characteristics of the instrumental detection methods, e.g., liquid chromatography tandem mass spectrometry [4]. Nonetheless, for detection of trace levels of target analytes such as dietary aflatoxins, it is equally important that sample collection and preparation procedures are also optimized for accurate and rapid determination of the mycotoxin content.

Aflatoxin detection methods include immunoassays [16,32], fluorimetry [18] and chromatographic methods [14,32-34] such as LC-MS/MS for multi-mycotoxin analysis [15,19]. While these methods have different performance, the largest uncertainty associated with the measurement of aflatoxin content is due to lack of homogeneity of the contaminant in food and feed leading to variability $[4,35]$. It is indeed not easy to get a representative sample $[11,36,37]$ that accurately estimates true aflatoxin content in a bulk consignment, as observed by Matumba et al. [38]. Another source of measurement uncertainty is bias, deviation from the true value due to sampling tools [39]. Aflatoxin analysis in food and feed is a three-step process: selection of the sample of a given size, sample preparation and quantification $[4,40]$. Development of chemical analysis often focuses on the last step, yet the sample selection step is the largest source of variability, followed by sample preparation, 
while quantification is the smallest contributor $[35,37,39,41]$. High variability necessitates increase in replicates to achieve required accuracy, thereby increasing the sample analysis turnaround time. There is need for test procedures with improved accuracy and precision for estimation of true aflatoxin exposure to ensure feed safety [36]. Recent data on aflatoxin contamination in figs [35] and maize [42] show that optimization of upstream procedures can considerably reduce the measurement uncertainty. In this study, sample selection, reduction and extraction steps were designed and validated to ensure representativeness of collected samples as well as appropriateness of the procedures and sampling tools used for estimation of aflatoxin residues in chicken feed. We first optimized sample selection procedures, and then incorporated a wet milling (water slurring) step in the feed sample preparation procedure, a critical modification that enhances sample homogenization more effectively than dry milling and a lesson learned from food analysis [35,39,41-43]. This reduces inter-assay variability and need for measurement replications thus decreasing sample analysis turnaround time. Because of lack of national, regional and international legal regulatory limits for AFB1 content in chicken feed, the EU legal framework was used as a reference in this study.

\section{Results and Discussion}

\subsection{Highlights of Major Modification of the Improved Aflatoxin Test Procedure}

The main modification in the five segments of the aflatoxin test procedure are as follows:

(a) Primary sampling or sample selection (number and size of incremental samples, type of sampling tools for open and closed sub-lots, random procedure, size of incremental and aggregate samples, Section 4.1.1)

(b) Secondary sampling (size of laboratory sample determined employing FAO Mycotoxin Sampling Tool, coning and quartering method improved by performing all coning and shoveling procedures under a steadfast funnel for mass-reduction of aggregate sample to $2 \mathrm{~kg}$ laboratory sample, Section 4.1.2)

(c) Tertiary sampling (size of test portion determined employing FAO Mycotoxin Sampling Tool, the improved coning and quartering method in Point (b) for massreduction of laboratory sample to $25 \mathrm{~g}$ test portion, Section 4.1.3)

(d) Quaternary sampling (homogenization and splitting of test portion by water slurring at matrix/water, 25:37.5, w/w; optimal matrix to organic solvent ratio for solid-liquid extraction, slurry/extraction solvent, 1.3:86.5, $w / v$, Section 4.1.4)

(e) Quantification of AFB1 (optimal organic solvent to aqueous buffer ratio for AFB1 extraction back to aqueous phase-modified extract to aqueous buffer mixture was modified to $80 \%$ acetonitrile extraction solvent: PBS-T mixture, 100:650, $v / v$, Section 4.1.5)

\subsection{Enzyme-Linked Immunosorbent Assay of Prepared Standards for Determination of Aflatoxin Content in Chicken Feed Samples}

Aflatoxin B1 cELISA, using AFB1-ELISA low matrix kit (Helica Biosystems Inc. ${ }^{\circledR}$, Santa Ana, CA, USA) is the last segment of the improved aflatoxin test procedure (Section 4.1) and its details are in Section 4.1.5. Curve-fitting characteristics of this immunoassay are shown in Figure 1. The four-parameter logistic curve (4PLC) of spiked aflatoxin B1 (AFB1) concentrations was characterized by two plateau regions and an inflection point (Figure 1). This curve was used to study linearity of measurements of AFB1 spiked in the modified extract to aqueous buffer mixture, $80 \%$ acetonitrile extraction solvent: PBS-T mixture $(100: 650, v / v)$.

$$
\text { Response (inhibition), } \mathrm{y}=\mathrm{a}-\mathrm{d} /[1+(\mathrm{x} / \mathrm{c}) \mathrm{b}]+\mathrm{d}
$$

where $\mathrm{x}=$ AFB1 concentration and $\mathrm{a}-\mathrm{d}$ are described in Table 1 . 


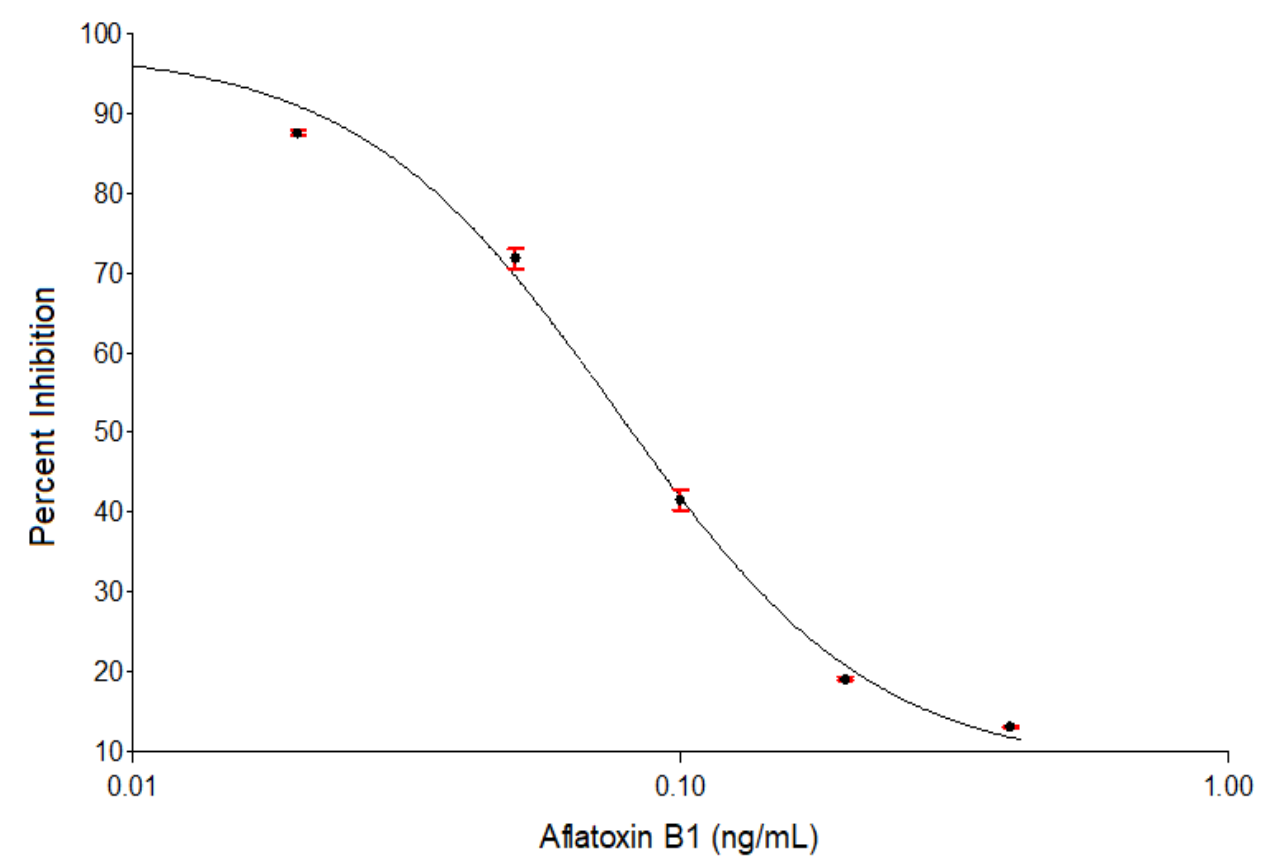

Figure 1. Four-parameter logistic standard curve of duplicate analysis of aflatoxin B1 standards in modified acetonitrile extract solvent: phosphate buffered saline-20 mixture (100:650,v/v). Extraction of aflatoxin B1 from organic into aqueous phase using the modified extraction solvent mixture did not affect the assay performance since the percent inhibition values were within the range specified by the manufacturer.

Table 1. Curve fitting characteristics for the AFB1-ELISA generated by AFB1 standards in modified acetonitrile extract solvent: phosphate buffered saline-20 mixture (100:650, $v / v)$ showing both values of the parameters (a-d) and linearityassociated coefficients $\left(\mathrm{r}\right.$ and $\left.\mathrm{r}^{2}\right)$.

\begin{tabular}{cccccc}
\hline \multicolumn{5}{c}{ Parameters Values of 4-Parameter Logistic Curve } \\
\hline $\begin{array}{c}\text { Maximum signal } \\
\text { intensity (a) }\end{array}$ & $\begin{array}{c}\text { Slope at inflection } \\
\text { point }(\mathrm{b})\end{array}$ & $\begin{array}{c}\text { Concentration at } \\
\text { inflection point } \\
\left(\left(50 \% \mathrm{~B} / \mathrm{B}_{0}\right), \mathrm{IC}_{50}(\mathrm{c})\right.\end{array}$ & $\begin{array}{c}\text { Minimum signal } \\
\text { intensity }(\mathrm{d})\end{array}$ & $\begin{array}{c}\text { Coefficients of } \\
\text { correlation }(\mathrm{r})\end{array}$ & $\begin{array}{c}\text { Coefficients of } \\
\text { determination }\left(\mathrm{r}^{2}\right)\end{array}$ \\
\hline 98.9 & 1.58 & $0.072 \mathrm{ng} / \mathrm{mL}$ & 5.6 & 0.998 & 0.997 \\
\hline
\end{tabular}

Numerous methods have been developed for analysis of aflatoxins in food and feed with high performance liquid chromatography (HPLC) as the gold standard. However, enzyme-linked immunosorbent assay (ELISA) has also been widely used given its many advantages over HPLC and other chromatographic techniques. ELISA is cost-effective because it does not need clean-up columns and expensive instrumentation, user-friendly, high-throughput, accurate and reproducible. One disadvantage of ELISAs is susceptibility to matrix effects, causing the reported analyte level to be falsely elevated or depressed. We used an ELISA method designed to be resistant to matrix interferences and which was previously validated to test disparate sample types, such as pet food [44], sorghum [45], maize [46], nuts, spices and many others [47]. Lack of requirement for sample clean-up and specialized equipment, skilled personnel for quantification by ELISA together with improved upstream sample handling procedures described herein, combined with high throughput (42 samples per run), guarantee rapid and reliable estimation of aflatoxin in complex and amorphous matrices such as animal feed. In addition, incorporation of a water slurring step in the extraction procedure reduces the number of test replications, considerably reducing sample analysis turnaround time. 


\subsection{Validation Results of the Improved Aflatoxin Test Procedure}

Details of experimental design used for method validation are given in Section 4.2.2. Fourteen groups of native pseudo blank feed aliquots were used for method validation (Table 2). Briefly, Groups I-V were used to evaluate extraction efficiency and repeatability studies of surrogate aflatoxin (spiked analyte), Groups IV-XI were used for replication studies (within laboratory repeatability and reproducibility) of native aflatoxin (naturally occurring analyte) and Groups XII-XIV were used to evaluate limits of detection (LOD) and quantification (LOQ).

Table 2. Experimental design for recovery, replication and limits of detection (LOD) and quantification (LOQ) determination studies. Spike and recovery studies utilized surrogate aflatoxin (Groups I-V), whereas replication, LOD and LOQ studies used native aflatoxin (Groups VI-XIV) in feed aliquots.

\begin{tabular}{|c|c|c|}
\hline Feed Aliquot Group & Extraction Conditions ${ }^{\varepsilon}$ & Study \\
\hline $\begin{array}{c}\mathrm{I} \\
(\mathrm{R}=6) *\end{array}$ & $\begin{array}{l}\text { (i) dry milling (ii) matrix } / \mathrm{ACN}^{\mathrm{a}}(25: 133, w / v) ;\left(\text { iii) } \mathrm{ACN}^{\mathrm{a}}\right. \\
\text { extract } / \mathrm{PBS}^{\mathrm{b}} \mathrm{T}^{\mathrm{b}}(10.6: 989.4, v / v) \text {, (iv) final dilution factor }=500\end{array}$ & \multirow{2}{*}{$\begin{array}{l}\text { Spike and recovery (comparison } \\
\text { of dry and wet milling) }\end{array}$} \\
\hline $\begin{array}{c}\mathrm{II} \\
(\mathrm{R}=6) *\end{array}$ & $\begin{array}{l}\text { (i) wet milling @ matrix/water }(25: 37.5, w / w) ;\left(\text { ii) slurry } / \mathrm{ACN}^{\mathrm{a}} \text {, }\right. \\
(2: 133, w / v) ;\left(\text { iii) } \mathrm{ACN}^{\mathrm{a}} \text { extract/PBS- } \mathrm{T}^{\mathrm{b}}(100: 650, v / v) \text {, (iv) final }\right. \\
\text { dilution factor }=1247\end{array}$ & \\
\hline III $(\mathrm{R}=10) *$ & $\begin{array}{c}\text { (i) wet milling @ matrix/water }(25: 37.5, w / w) ;\left(\text { ii) slurry } / \mathrm{ACN}^{\mathrm{a}} \text {, }\right. \\
(1.3: 130, w / v) ;\left(\text { iii) } \mathrm{ACN}^{\mathrm{a}} \text { extract/PBS-T } \mathrm{b}(100: 900, v / v) \text {, (iv) final }\right. \\
\text { dilution factor }=2500\end{array}$ & \multirow{3}{*}{$\begin{array}{l}\text { Spike and recovery studies } \\
\text { (comparison of three extraction } \\
\text { conditions used in wet milling) }\end{array}$} \\
\hline IV $(\mathrm{R}=10)$ * & $\begin{array}{l}\text { (i) wet milling @ matrix/water }(25: 37.5, w / w) ;(i i) \text { slurry } / \mathrm{ACN}^{\mathrm{a}} \text {, } \\
(1.3: 65, w / v) ;\left(\text { iii) } \mathrm{ACN}^{\mathrm{a}} \text { extract/PBS-T } \mathrm{b}(100: 900, v / v) \text {, (iv) final }\right. \\
\text { dilution factor }=1250\end{array}$ & \\
\hline $\begin{array}{c}\mathrm{V} \\
(\mathrm{R}=10) *\end{array}$ & 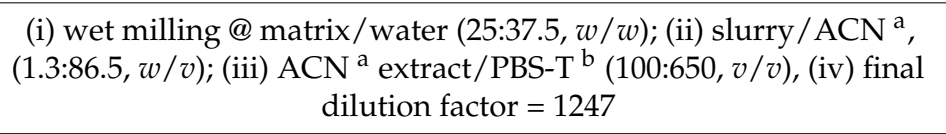 & \\
\hline $\begin{array}{c}\mathrm{VI} \\
(\mathrm{R}=10)\end{array}$ & $\begin{array}{l}\text { (i) dry milling (ii) matrix } / \mathrm{ACN}^{\mathrm{a}}(25: 130, w / v) ;\left(\text { iii) } \mathrm{ACN}^{\mathrm{a}}\right. \\
\text { extract/PBS-T }^{\mathrm{b}}(100: 900, v / v) \text {, (iv) final dilution factor }=52\end{array}$ & \multirow{4}{*}{$\begin{array}{l}\text { Intra-laboratory variability } \\
\text { (Repeatability) }\end{array}$} \\
\hline VII $(\mathrm{R}=10)$ & $\begin{array}{c}\text { (i) wet milling @ matrix/water }(25: 37.5, w / w) ;\left(\text { ii) slurry } / \mathrm{ACN}^{\mathrm{a}} \text {, }\right. \\
(1.3: 130, w / v) ; \text { (iii) } \mathrm{ACN}^{\mathrm{a}} \text { extract/PBS- } \mathrm{b}(100: 900, v / v) \text {, (iv) final } \\
\text { dilution factor }=2500\end{array}$ & \\
\hline VIII (R = 10) & $\begin{array}{l}\text { (i) dry milling (ii) matrix } / \mathrm{ACN}^{\mathrm{a}}(1.3: 130, w / v) ;\left(\text { iii) } \mathrm{ACN}^{\mathrm{a}}\right. \\
\text { extract/PBS-T }{ }^{\mathrm{b}}(100: 900, v / v) \text {, (iv) final dilution factor }=1000\end{array}$ & \\
\hline $\begin{array}{c}\mathrm{IX} \\
(\mathrm{R}=10)\end{array}$ & $\begin{array}{c}\text { (i) wet milling @ matrix/water }(25: 37.5, w / w) ;\left(\text { ii) slurry } / \mathrm{ACN}^{\mathrm{a}} \text {, }\right. \\
(1.3: 130, w / v) ;\left(\text { iii) } \mathrm{ACN}^{\mathrm{a}} \text { extract/PBS-T }{ }^{\mathrm{b}}(100: 900, v / v) \text { (iv) final }\right. \\
\text { dilution factor }=2500\end{array}$ & \\
\hline $\begin{array}{c}X \\
(\mathrm{R}=15)\end{array}$ & $\begin{array}{l}\text { (i) wet milling @ matrix/water }(25: 37.5, w / w) ;\left(\text { ii) slurry } \mathrm{n} / \mathrm{ACN}^{\mathrm{a}} \text {, }\right. \\
(1.3: 130, w / v) ;\left(\text { iii) } \mathrm{ACN}^{\mathrm{a}} \text { extract: } \mathrm{PBS}^{\mathrm{b}} \mathrm{\textrm {b }}(100: 900, v / v) ;(\mathrm{iv}) \text { final }\right. \\
\text { dilution factor }=2500\end{array}$ & \multirow{2}{*}{$\begin{array}{l}\text { Intermediate variability } \\
\text { (within-laboratory } \\
\text { reproducibility) }\end{array}$} \\
\hline $\begin{array}{c}\mathrm{XI} \\
(\mathrm{R}=15)\end{array}$ & $\begin{array}{c}\text { (i) wet milling @ matrix/water }(25: 37.5, w / w) ;\left(\text { ii) slurry } / \mathrm{ACN}^{\mathrm{a}} \text {, }\right. \\
(1.3: 86.5, w / v) ;\left(\text { iii) } \mathrm{ACN}^{\mathrm{a}} \text { extract/PBS-T }{ }^{\mathrm{b}}(100: 650, v / v) \text { (iv) Final }\right. \\
\text { dilution factor }=1247\end{array}$ & \\
\hline $\begin{array}{c}\text { XII } \\
(\mathrm{R}=4)\end{array}$ & $\begin{array}{c}\text { (i) dry milling (ii) } \mathrm{ACN}^{\mathrm{a}} \text { extract/PBS- } \mathrm{T}^{\mathrm{b}}(1: 1000, v / v) \text { (iii) final } \\
\text { dilution factor }=1000\end{array}$ & \multirow{3}{*}{ Determination of LOD and LOQ } \\
\hline XIII (R = 5) & $\begin{array}{l}\text { (i) dry milling } \mathrm{ACN}^{\mathrm{a}} \text { extract/ACN }{ }^{\mathrm{a}} / \mathrm{PBS}^{\mathrm{T}} \mathrm{T}^{\mathrm{b}}(1: 5: 100, v / v / v) \text { (ii) } \\
\text { final dilution factor }=500\end{array}$ & \\
\hline XIV (R = 5) & $\begin{array}{l}\text { (i) wet milling (ii) } \mathrm{ACN}^{\mathrm{a}} \text { extract } / \mathrm{PBS}^{\mathrm{b}} \mathrm{T}^{\mathrm{b}}(1: 1247, v / v) \text { (iii) final } \\
\text { dilution factor }=1247\end{array}$ & \\
\hline
\end{tabular}

${ }^{\varepsilon}$ Extraction conditions here mean sample homogenization, solid-liquid and liquid-liquid extraction solvent mixture components with Roman numbers (i-iii) standing for specific conditions whose details can be found in Sections 4.2.2-4.2.4; $\mathrm{R}$ is $\mathrm{n}=$ number of replicates; * number of " 0 " ppb feed aliquots not included in $n . ;{ }^{\text {a }}$ acetonitrile:water $(80: 20, v / v)$; ${ }^{b}$ phosphate buffered saline tween 20. 
We modified primary sampling procedures to improve representativeness and ensure sample integrity. Uncertainty associated with sample selection was minimized through careful calculation of incremental and laboratory samples' size using granulometry and particle size of matrix, together with increased number and size of test portions $[39,40]$, correct design of sampling equipment to eliminate bias and random sampling procedures $[48,49]$. Specifically, the incremental samples were optimally spaced [48]. Sample size, sample selection and handling are usually dismissed as a "simple procedure", but they are major source of variation. Attention should be given to the sample selection process for a given sample size as described herein.

\subsubsection{Method Accuracy and Precision}

Extraction efficiency and variability associated with various aflatoxin extraction procedures for recovery studies are shown in Table 3 and raw data in Supplementary Materials (Dataset S1. Aflatoxin recovery data). Wet milling method (Group II) had mean aflatoxin recovery of $121 \%$, which at $p=0.05$ is not significantly different from mean recovery of $80 \%$ of conventional dry milling procedure (Group I). For estimation of spiked aflatoxin, variability associated with dry milling was significantly higher compared to wet milling. Coefficient of variation (CV) also referred to as relative standard deviation (RSD) of dry milling procedure (Group I) was 2.3-fold compared to slurry, wet milling method (Group II). CV effect associated with Group II (wet milling procedure) was less (CV rank 2) compared to CV rank 4 of Group I (dry procedure) (Table 3). Multiple comparisons employing Welch ANOVA-associated Games-Howell post-hoc test showed that mean aflatoxin recovery associated with Group III procedure was significantly $(p<0.05)$ different from those of both Groups IV and V (Table 3). Of the three wet milling methods, variability (Observed CV) associated with Group V (CV rank 1) was remarkably low compared to Groups III (1.5-fold) and IV (3-fold) procedures. Additionally, Group V had the least bias and repeatability precision (HorRat value $<1$ ). Wet milling procedure associated with Groups II and V had acceptable precision level (expressed as CV or RSD) as prescribed by modified Horwitz equation. Analyzed together, the extraction procedure associated with Groups II and V had the lowest percent bias of -4.95 , acceptable variability and recovery (Table 3: HorRat value $<2$; recovery $=95 \%$ )

Precision (variability) was evaluated using the Horwitz equation where the measure of variation, predicted relative standard deviation $\left(\mathrm{RSD}_{\mathrm{p}}\right)$ or $\mathrm{CV}$ is a function of the analyte concentration [50-54]. This is given by modified and unmodified Horwitz equations:

$$
\begin{aligned}
& \text { For modified Horwitz equation, } \mathrm{RSD}_{\mathrm{p}}<2^{(1-0.5 \log \mathrm{C})} \times 0.67 \\
& \text { For unmodified Horwitz equation, } \mathrm{RSD}_{\mathrm{p}}<2^{(1-0.5 \log \mathrm{C})}
\end{aligned}
$$

where $\mathrm{C}=\mathrm{AFB} 1$ concentration.

The modified Horwitz equation was used to predict RSD under repeatability and routine inter-assay conditions while the unmodified form was used for within-laboratory reproducibility conditions (intermediate precision). The observed relative standard deviation $\left(\mathrm{RSD}_{\mathrm{O}}\right)$ was compared with the $\mathrm{RSD}_{\mathrm{p}}$ to give a Horwitz Ratio (HorRat) value, thus:

$$
\text { HorRat value }=\mathrm{RSD}_{\mathrm{O}} / \mathrm{RSD}_{\mathrm{p}}
$$

During method validation, the Commission of the European Communities (CEC) precision requirement for both repeatability and within-laboratory reproducibility conditions is a HorRat value < 2 [55]. However, for routine work (Sections 2.3.5 and 4.2.8), we adopted inter-assay precision level of HorRat $\leq 1$ [56].

Variability associated with estimation of natural AFB1 in chicken feed employing two sample splitting techniques at two sampling stages are shown in Table 4 and raw data in supplementary material (Dataset S2. Precision data). HorRat values for repeatability (HorRat ${ }_{\mathbf{r}}$ ) and within-laboratory reproducibility (HorRat ${ }_{\mathbf{R}}$ ) ranged 0.3-5.8 and 0.9-1.3, respectively, with all groups but one having HorRat values below the maximum allowable 
limit of 2 set by European legislation [55]. The lowest intra-laboratory variation was observed in secondary sampling for splitting $25 \mathrm{~g}$ dry aliquots from the laboratory sample $\left(\right.$ Group VI; $\mathrm{RSD}_{\mathrm{r}}=6.5 \%$, HorRat $\mathrm{r}_{\mathrm{r}}$ value $=0.3$; rank $\mathrm{H} 1$ ), and highest for preparing $1.3 \mathrm{~g}$ dry aliquots at tertiary sampling employing modified coning and quartering procedure (Group VIII; $\mathrm{RSD}_{\mathrm{r}}=91.5 \%$, HorRat ${ }_{\mathrm{r}}$ value $=5.8$; rank H6). For preparation of $1.3 \mathrm{~g}$ analytical samples, intra-laboratory variation associated with coning and quartering procedure (Group VIII) was 4.4-fold that for water slurry (wet milling) method (Group IX, $\mathrm{RSD}_{\mathbf{r}}=20.6 \%$, rank $\mathrm{H} 3$ ). At tertiary sampling stage, intermediate precision (within-laboratory reproducibility) associated with Group X $\left(\mathrm{RSD}_{\mathbf{R}}=30.3 \%\right.$, HorRat $\mathbf{R}_{\mathbf{R}}$ value $=1.3$, rank $\left.\mathrm{H} 4\right)$ and Group XI $\left(\mathrm{RSD}_{\mathbf{R}}=26.9 \%\right.$, HorRat $\mathbf{R}_{\mathbf{R}}$ value $=0.9$, rank $\left.\mathrm{H} 2\right)$ of water slurry procedure were almost the same (HorRat value $>2$ ), the latter having slightly lower variability. One-way ANOVA showed no significant effect $(p>0.05)$ of the analyst or the day of analysis on means of AFB1 levels for each condition of the two water slurry procedures.

The second most important source of variability after sample collection is the sample preparation segment of the aflatoxin test procedure [41,48]. Variability associated with splitting $25 \mathrm{~g}$ test portions from the comminuted laboratory sample employing modified coning and quartering procedure was much below the threshold level prescribed by European Union [52] and therefore suitable mass reduction method for this purpose. Density effects and matrix particle size influence performance of sample splitting methods [57]. We minimized this by efficient dry comminution of the aggregate sample prior to mass reduction [58]. Preparation of smaller size aliquots did not yield desirable precision under intra-laboratory conditions. Indeed, the FAO sampling tool [59] will not accept mass reduction in granular products beyond paired $25 \mathrm{~g}$ test portions for aflatoxin analysis because this will compromise representativeness. To enhance sampling precision, aggregate sample collected should not be less than $2 \mathrm{~kg}$. Variability at this level can be reduced by increasing aggregate sample size before comminution through collection of $200 \mathrm{~g}$ incremental samples from all potential sampling locations. Removal of test portions larger than $25 \mathrm{~g}$ from a $2 \mathrm{~kg}$ (or larger) comminuted laboratory sample will reduce variability and can still be water slurried and a small $(1.3 \mathrm{~g})$ slurry aliquot selected for extraction. There are also commercial laboratory mills that incorporate a sample-splitting mechanism $[4,41]$. However, these are expensive and not readily available. Our novel aflatoxin test procedure is designed especially for laboratories that do not have automated sample splitting facilities.

Another critical innovation described here is inclusion of wet milling (water slurring), an additional comminuting step in the extraction procedure followed by processing of a smaller slurry aliquot. This allowed analysis of an adequately large test portion (25 $\mathrm{g}$ and larger), minimizing huge sampling uncertainty associated with aflatoxin estimation in animal feed and with reduced extraction cost. As reported in the literature, aflatoxin contamination is characterized by heterogeneous spatial distribution and nugget effect $[37,60]$. Wet milling is more efficient than dry milling in producing a more homogenous sample $[35,39,43,61]$. Indeed, water slurring was recently incorporated as a sample homogenizing procedure for aflatoxin analysis in maize [42] and dried figs [35]. This is the first report of using wet milling sample preparation method for aflatoxin analysis in animal feed. Through optimization of sample selection and mass reduction procedures and minimizing spatial heterogeneity of aflatoxin distribution in the test portion by wet milling, we were able to reasonably reduce measurement uncertainty and extraction cost. However, our modification does not completely eradicate inherent variability associated with sample selection, sample preparation and analytical steps of the aflatoxin test procedure, but minimizes this variability at each step, as well as reducing bias at both test portion selection and analytical segment. The aflatoxin diagnosis kit used in this study was not validated specifically for chicken feed. It is designed for various food matrices and animal feed grouped as one matrix. Because animal feed is an amorphous matrix with diverse physicochemical properties which can be a source of variation due to within-class matrix effects [62], we generated validation data associated with chicken feed. Single-laboratory validation of the modified aflatoxin test procedure was carried out through collection of 
data on spiking and recovery, replication, LOD and LOQ, robustness and ruggedness as the CEC prescribes [50-52,54,63].

Accuracy is a trade-off between bias and recovery data variability. We observed least bias $(-4.95)$ and good aflatoxin recovery $(95.1 \%)$ in wet milling procedure (Group. V). Recovery, precision and efficiency were compliant with CEC requirements of $75-125 \%$ for recovery and HorRat $<2$ for precision $[52,54,64]$. AOAC and other authorities also recognize HorRat $<2$ as a reliable precision criterion [64-66]. For replication studies using native aflatoxin, precision data collected under repeatability and reproducibility conditions met the EU guidelines. In absence of collaborative trial data, we estimated inter-laboratory precision using modified Horwitz equation against our within-laboratory reproducibility data, an internationally accepted practice [62]. Repeatability was both within the EU requirements and the same range for surrogate and native aflatoxin contents. Since native aflatoxin contamination is characterized by heterogeneity [4,35], we attribute the observed reduced variability to effective sample homogenization through the wet milling innovative procedure in our novel method described herein. By CEC requirements, the wet milling method described here has good repeatability and reproducibility. Reducing intrinsic variability associated with aflatoxin heterogeneity is cost effective in terms of time and resources [67].

Table 3. Extraction efficiency (percent recovery), bias and measurement precision of surrogate AFB1 content in chicken feed associated with dry and wet sample homogenization procedures at various extraction conditions (dilution factors) and ranked using HorRat* value effect.

\begin{tabular}{|c|c|c|c|c|c|c|c|c|c|c|c|c|c|}
\hline \multirow[b]{2}{*}{$\begin{array}{l}\text { Milling } \\
\text { Method }\end{array}$} & \multirow[b]{2}{*}{ Group } & \multicolumn{6}{|c|}{ Aflatoxin Extraction Conditions } & \multirow{2}{*}{$\begin{array}{c}* \text { Mean } \\
\text { AFB1 \% } \\
\text { Recovery }\end{array}$} & \multirow[b]{2}{*}{$\begin{array}{c}\% \\
\text { Bias }\end{array}$} & \multicolumn{4}{|c|}{ Measurement Variability } \\
\hline & & $\begin{array}{c}\text { Expected } \\
\text { Concentration }\end{array}$ & $\begin{array}{l}\text { Size of } \\
\text { Analytical } \\
\text { Sample }\end{array}$ & $\begin{array}{l}\text { DF of } \\
\text { Water } \\
\text { Slurry }\end{array}$ & $\begin{array}{c}\text { DF in } \\
\text { ACN * }\end{array}$ & $\begin{array}{l}\text { DF in } \\
\text { PBS- }^{b}\end{array}$ & $\begin{array}{l}\text { Final } \\
\text { DF }\end{array}$ & & & StDev. & $\mathrm{CV}$ & $\begin{array}{c}\mathrm{CV} \\
\text { Effect }\end{array}$ & $\begin{array}{c}\text { HorRat } \\
* * \text { Value }\end{array}$ \\
\hline \multirow{3}{*}{ Dry } & \multirow{3}{*}{$\begin{array}{c}I \\
(R=6)\end{array}$} & $20 \mathrm{ppb}(\mathrm{R}=3)$ & \multirow{3}{*}{$25 \mathrm{~g}$} & \multirow{3}{*}{-} & \multirow{3}{*}{5.3} & \multirow{3}{*}{94.3} & \multirow{3}{*}{500} & 57 & & \pm 6 & 10.9 & & 0.57 \\
\hline & & $100 \mathrm{ppb}(\mathrm{R}=3)$ & & & & & & 103 & & \pm 13 & 12.4 & & 0.82 \\
\hline & & All replicates & & & & & & $80^{\mathrm{a}}$ & -20 & \pm 26 & 33.1 & $9.5^{\mathrm{R} 4}$ & $\begin{array}{l}0.57- \\
0.82\end{array}$ \\
\hline \multirow{3}{*}{ Wet } & \multirow{3}{*}{$\begin{array}{c}\text { II } \\
(\mathrm{R}=6)\end{array}$} & $20 \mathrm{ppb}(\mathrm{R}=3)$ & \multirow{3}{*}{$2 \mathrm{~g}$} & \multirow{3}{*}{2.5} & \multirow{3}{*}{66.5} & \multirow{3}{*}{7.5} & \multirow{3}{*}{1247} & 119 & & \pm 25 & 21.2 & & 0.95 \\
\hline & & $100 \mathrm{ppb}(\mathrm{R}=3)$ & & & & & & 123 & & \pm 9 & 7.4 & & 0.8 \\
\hline & & All replicates & & & & & & $121^{\mathrm{a}}$ & 21 & \pm 17 & $14.1^{\mathrm{h}}$ & $-9.5^{\mathrm{R} 2}$ & $0.8-0.95$ \\
\hline \multirow{9}{*}{ Wet } & \multirow{3}{*}{$\begin{array}{c}\text { III } \\
(\mathrm{R}=10)\end{array}$} & $20 \mathrm{ppb}(\mathrm{R}=5)$ & \multirow{3}{*}{$1.3 \mathrm{~g}$} & \multirow{3}{*}{2.5} & \multirow{3}{*}{100} & \multirow{3}{*}{10} & \multirow{3}{*}{2500} & 145 & & \pm 19 & 12.8 & & 0.58 \\
\hline & & $100 \mathrm{ppb}(\mathrm{R}=5)$ & & & & & & 112 & & \pm 9 & 17.4 & & 0.44 \\
\hline & & All replicates & & & & & & $129^{b, c}$ & 29 & \pm 22 & 17.2 & $-3.8^{\mathrm{R} 3}$ & $\begin{array}{l}0.44- \\
0.58\end{array}$ \\
\hline & \multirow{3}{*}{$\begin{array}{c}\text { IV } \\
(\mathrm{R}=10)\end{array}$} & $20 \mathrm{ppb}(\mathrm{R}=5)$ & \multirow{3}{*}{$1.3 \mathrm{~g}$} & \multirow{3}{*}{2.5} & \multirow{3}{*}{50} & \multirow{3}{*}{10} & & 49 & & \pm 12 & 23.2 & & 1.04 \\
\hline & & $100 \mathrm{ppb}(\mathrm{R}=5)$ & & & & & 1250 & 85 & & \pm 15 & 18.1 & & 1.04 \\
\hline & & All replicates & & & & & & $67^{b}$ & -33 & \pm 23 & 34.2 & $13.3^{\mathrm{R} 5}$ & 1.04 \\
\hline & & $20 \mathrm{ppb}(\mathrm{R}=5)$ & & & & & & 80 & & \pm 13 & 15.8 & & 0.71 \\
\hline & V & $100 \mathrm{ppb}(\mathrm{R}=5)$ & $1.3 \mathrm{~g}$ & 2.5 & 66.5 & 7.5 & 1247 & 80 & & \pm 6 & 6.9 & & 0.39 \\
\hline & $(K=10)$ & All replicates & & & & & & $80^{c}$ & -20 & \pm 9 & 11.5 & $-9.5^{\mathrm{R} 1}$ & $\begin{array}{l}0.39- \\
0.71\end{array}$ \\
\hline & & $20 \mathrm{ppb}(\mathrm{R}=8)$ & & & & & & 94 & & \pm 26 & 27.6 & & 1.24 \\
\hline $\begin{array}{l}\text { Groups } \\
\text { replicate }\end{array}$ & $\begin{array}{l}\text { and V } \\
\text { analyzed }\end{array}$ & $100 \mathrm{ppb}(\mathrm{R}=8)$ & - & 2.5 & 66.5 & 7.5 & 1247 & 96 & & \pm 23 & 24.1 & & 1.38 \\
\hline togethe & $(\mathrm{R}=16)$ & All replicates & & & & & & 95 & -5 & \pm 24 & 25.0 & & $\begin{array}{l}1.24- \\
1.38\end{array}$ \\
\hline
\end{tabular}

** Observed residue standard deviation/predicted residue standard deviation; $\mathrm{R}$ is $\mathrm{n}=$ number of replicates; ${ }^{*}$ acetonitrile:water (80:20, $v / v)$, ${ }^{a}$ figures marked with this superscript were statistically compared by independent $t$-test; ${ }^{b}$ phosphate buffered saline tween 20 ; DF Dilution factor; StDev, Standard deviation; CV, Coefficient of variation (relative standard deviation); ${ }^{\text {,c }}$ figures marked with the same superscript were statistically compared by Welch's ANOVA (Games-Howel post-hoc test); R1-5 method ranking based on CV effect with descending order of preference; ${ }^{*} 75-125 \%$ mean recovery is the accepted recovery range for trace AFB1 levels [52]. 
Table 4. Within laboratory repeatability and reproducibility associated with measurement of native aflatoxin content in chicken feed at secondary and tertiary sampling stages after sample homogenization employing by either dry or wet (water slurring) milling techniques. Variability values were determined under different extraction conditions and ranked using HorRat * value effect.

\begin{tabular}{|c|c|c|c|c|c|c|c|c|c|c|c|c|}
\hline \multirow{3}{*}{$\begin{array}{l}\text { Sampling } \\
\text { Stage }\end{array}$} & \multicolumn{6}{|c|}{ Intra-Laboratory Assay Precision (Within-Laboratory Repeatability) } & \multicolumn{6}{|c|}{ Intermediate Precision (Within-Laboratory Reproducibility) } \\
\hline & \multirow{2}{*}{$\begin{array}{l}\text { Group } \\
\text { Number/ } \\
\text { Mass } \\
\text { Reduction } \\
\text { Method }\end{array}$} & \multirow{2}{*}{$\begin{array}{c}\text { Milling } \\
\text { Method } \\
\text { and Size of } \\
\text { Analytical } \\
\text { Sample }\end{array}$} & \multirow[b]{2}{*}{ EC } & \multirow{2}{*}{$\begin{array}{c}\text { AFB1 } \\
\text { Level } \\
(\mathrm{ppb}) \\
\text { Mean } \pm \\
\text { Sd. }\end{array}$} & \multicolumn{2}{|c|}{ Variability } & \multirow{2}{*}{$\begin{array}{l}\text { Group } \\
\text { Number/ } \\
\text { Mass Re- } \\
\text { duction } \\
\text { Method }\end{array}$} & \multirow{2}{*}{$\begin{array}{l}\text { Milling } \\
\text { Method } \\
\text { and Size of } \\
\text { Analytical } \\
\text { Sample }\end{array}$} & \multirow[b]{2}{*}{ EC } & \multirow{2}{*}{$\begin{array}{c}\text { AFB1 } \\
\text { Level } \\
\text { (ppb) } \\
\text { Mean } \pm \\
\text { Sd } \\
\end{array}$} & \multicolumn{2}{|c|}{ Variability } \\
\hline & & & & & $\operatorname{RSD}_{\mathrm{r}}$ & $\begin{array}{c}\text { HorRat } \\
\text { ValueEffect }\end{array}$ & & & & & $\operatorname{RSD}_{\mathrm{R}}$ & $\begin{array}{c}\text { HorRat } \\
\text { Value } \\
\text { Effect }\end{array}$ \\
\hline Secondary & $\begin{array}{l}\text { Group VI } \\
\text { Coning and } \\
\text { quartering } \\
(\mathrm{R}=10)\end{array}$ & Dry $25 \mathrm{~g}$ & 1 & $15 \pm 1$ & 6.5 & $0.3^{\mathrm{H} 1}$ & & & & & & \\
\hline Tertiary & $\begin{array}{l}\text { Group VII } \\
\text { Water slurry } \\
(\mathrm{R}=10)\end{array}$ & Wet $1.3 \mathrm{~g}$ & 2 & $68 \pm 17$ & 24.5 & $1.5^{\mathrm{H} 5}$ & $\begin{array}{l}\text { Group X } \\
\text { Water } \\
\text { slurry } \\
(\mathrm{R}=15)\end{array}$ & Wet $1.3 \mathrm{~g}$ & 2 & $69 \pm 21$ & 30.3 & $1.3^{\mathrm{H} 4}$ \\
\hline Tertiary & $\begin{array}{l}\text { Group VIII } \\
\text { Coning and } \\
\text { quartering } \\
(\mathrm{R}=10)\end{array}$ & Dry $1.3 \mathrm{~g}$ & 3 & $73 \pm 67$ & 91.5 & $5.8^{\mathrm{H} 6}$ & $\begin{array}{l}\text { Group } \\
\text { XI } \\
\text { Water } \\
\text { slurry } \\
(\mathrm{R}=15)\end{array}$ & Wet $1.3 \mathrm{~g}$ & 4 & $19 \pm 5$ & 26.9 & $0.9^{\mathrm{H} 2}$ \\
\hline Tertiary & $\begin{array}{l}\text { Group IX } \\
\text { Water slurry } \\
(\mathrm{R}=10)\end{array}$ & Wet $1.3 \mathrm{~g}$ & 2 & $50 \pm 10$ & 20.6 & $1.2^{\mathrm{H} 3}$ & & & & & & \\
\hline
\end{tabular}

* Observed residue standard deviation/predicted residue standard deviation; $\mathrm{R}$ is $\mathrm{n}=$ number of replicates; EC (Extraction conditions) 1 enumerated as i-iv: (i) dry milling (ii) matrix / 80\% acetonitrile $(25: 130, w / v)$; (iii) $80 \%$ acetonitrile extract/ phosphate buffered saline tween $20(100: 900, v / v)$; (iv) final dilution factor = 52: EC 2 enumerated as i-iv: (i) wet milling with matrix/water $(25: 37.5, w / w)$; (ii) slurry $/ 80 \%$ acetonitrile $(1.3: 130, w / v)$; (iii) $80 \%$ acetonitrile extract/ phosphate buffered saline tween $20(100: 900, v / v)$; (iv) final dilution factor $=2500$ : EC 3 enumerated as i-iv: (i) dry milling; (ii) matrix/ 80\% acetonitrile (1.3:130, w/v); (iii) 80\% acetonitrile extract/ phosphate buffered saline tween $20(100: 900, v / v)$; (iv) final dilution factor = 1000: EC 4 enumerated as i-iv: (i) wet milling with matrix/water (25:37.5, $w / w)$; (ii) slurry $/ 80 \%$ acetonitrile $(1.3: 86.5, w / v)$; (iii) $80 \%$ acetonitrile extract/ phosphate buffered saline tween $20(100: 650, v / v)$; (iv) final dilution factor $=1247: \mathrm{Sd}$, Standard deviation; $\mathrm{RSD}_{\mathbf{r}}$, within-laboratory repeatability relative standard deviation; $\mathrm{RSD}_{\mathbf{R}}$, within-laboratory reproducibility relative standard deviation; ${ }^{\mathrm{H} 1-6}$ method ranking based on HorRat value effect with descending order of preference.

\subsubsection{Limits of Detection (LOD) and Quantification (LOQ) Values}

LOD and LOQ values associated with different sample preparation procedures are shown in Table 5 and raw data in Supplementary Materials (Dataset S3. LOD and LOQ data). The wet milling (slurry) procedure exhibited the strongest and most stable signals with the highest signal-to-noise ratio. These conditions yielded the lowest LOD $(7.5 \mathrm{ppb})$ and the only value below the EU legal limit for AFB1 residues in animal feed of $10 \mathrm{ppb}$ [23]. LOD and LOQ values associated with the slurry procedure were 7.5 and $16.0 \mathrm{ppb}$, respectively.

According to EU requirement, the maximum allowable AFB1 content in complete feed is $50 \mathrm{ppb}$ (adult cattle, sheep and goats), $20 \mathrm{ppb}$ (adult pigs and poultry) and $10 \mathrm{ppb}$ (young animals) [23]. The LOD of our method is $7.5 \mathrm{ppb}$, well below the lowest regulatory limit. Other quantification methods can be incorporated with an obvious advantage of lowering LOD if so desired. Alternatively, levels below LOD can be estimated by extrapolation using a company program [68], substituting the values with the LOD divided by the square root of two [69] or replacing by half the LOD value if the below LOD results are less than $60 \%$ of the data [70,71], the latter being an approach used by several workers [72-75]. 
Table 5. Limits of detection (LOD) and quantification (LOQ) values associated with dry and wet (water slurring) sample homogenization procedures for chicken feed at different extraction conditions (dilution factors). The LOD and LOQ values were derived from signal and noise of baseline native aflatoxin content expressed as absorbance.

\begin{tabular}{|c|c|c|c|}
\hline \multirow{3}{*}{ Baseline Response (OD) Statistics } & \multicolumn{3}{|c|}{ Limits of Detection and Quantification in $\mu \mathrm{g}$ AFB1 Per kg of Chicken Feed } \\
\hline & \multicolumn{2}{|c|}{ Dry Milling } & \multirow{2}{*}{$\begin{array}{c}\text { Wet Milling } \\
\text { Group XIV }(\mathrm{R}=5)(\text { Final } \\
\text { Dilution Factor }=1247)\end{array}$} \\
\hline & $\begin{array}{l}\text { Group XII }(\mathrm{R}=4) \text { (Final } \\
\text { Dilution Factor }=1000)\end{array}$ & $\begin{array}{l}\text { Group XIII }(\mathrm{R}=5)(\text { Final } \\
\text { Dilution Factor }=500)\end{array}$ & \\
\hline $\begin{array}{c}\text { Mean-2StDev } \\
\text { (Limit of detection) }\end{array}$ & 16.3 & 10.6 & 7.5 \\
\hline $\begin{array}{c}\text { Mean-5StDev } \\
\text { (Limit of quantification) }\end{array}$ & 31 & 22.3 & 16 \\
\hline \multirow{2}{*}{ Baseline response (OD) statistics } & \multicolumn{3}{|c|}{ Magnitude of signal, noise, their ratio and precision (absorbance) } \\
\hline & Group XII & Group XIII & Group XIV \\
\hline $\mathrm{B}_{0}$ & 1.773 & 1.752 & 1.871 \\
\hline StDev (blank) & 0.0399 & 0.0485 & 0.0339 \\
\hline Signal/noise ratio & 44.44 & 36.12 & 55.19 \\
\hline Coefficient of variance & 2.34 & 2.99 & 1.97 \\
\hline
\end{tabular}

$\mathrm{R}$ is $\mathrm{n}=$ number of replicates; OD, optical density; $\mathrm{B}_{0}$, average $\mathrm{OD}$ of the 0 standard; Mean, average of $\mathrm{B}_{0}$ OD values; StDev, standard deviation of OD values of blank feed material.

\subsubsection{Linearity}

Expected and observed AFB1 concentration values of the prepared standards are shown in Table 6 . There was significant $(p<0.01)$ negative correlation between ODs and measured aflatoxin levels of the prepared standards (Pearson correlation coefficient, $r=-0.932$ ). The expected and observed aflatoxin levels of the standards had a significant $(p<0.01)$ positive correlation (Pearson correlation coefficient, $r=0.961)$. The linear response range of the assay is $0.02-0.4 \mathrm{ng} / \mathrm{mL}$, beyond which linearity was lost (Table 6). These results and curve-fitting characteristics (Figure 1) indicate that the modified sample preparation conditions did not affect the assay range. Values of coefficients of correlation and determination (Section 2.2) showed good linearity of measured inhibition and AFB1 concentration in the range of $0.02-0.4 \mathrm{ng} / \mathrm{mL}$.

\subsubsection{Robustness and Ruggedness of the Aflatoxin Extraction Procedure}

For robustness data, Groups II and V (slurry extraction method at final dilution factor of 1247) had HorRat values of less than 2 (Table 3), indicating stable extraction efficiency precision of the improved aflatoxin test procedure under intra-laboratory repeatability conditions suggesting more satisfactory robustness compared to the other extraction conditions (see raw data at Dataset S1. Aflatoxin recovery data of supplementary files). For ruggedness results, HorRat value for Group X (final dilution factor $=2500$ ) was greater than 1 but less than 2, while, for Group XI (final dilution factor $=1247$ ), it was less than 1 (Table 4), indicating more stable precision under reproducibility conditions for Group XI (see raw data at Dataset S2. Precision data of supplementary files). This suggests that the improved aflatoxin test procedure has more satisfactory ruggedness (Group XI) compared to the other extraction conditions. Efficiency of extraction solvent stored at ambient temperature were $79 \%, 80 \%$ and $74 \%$, respectively (see raw data at Dataset S4. Robustnessruggedness data of supplementary files), for freshly prepared, one- and three-month-old $80 \%$ acetonitrile:water $(80: 20, v / v)$. The HorRat value associated with these data was 0.22 , suggesting minimal variability indicating stability of the solvent as an extraction solvent for AFB1 at ambient temperature for three months and satisfactory method ruggedness. 
Table 6. Linearity of aflatoxin B1 standard solutions in modified acetonitrile extract solvent: phosphate buffered saline tween 20 mixture $(100: 650, v / v)$. The values are mean of duplicate analysis.

\begin{tabular}{ccccccc}
\hline & \multicolumn{5}{c}{ Concentration and Optical Density of AFB1 Standard Solutions } \\
\cline { 2 - 7 } & Solution 1 & Solution 2 & Solution 3 & Solution 4 & Solution 5 & Solution 6 \\
\hline $\begin{array}{c}\text { Spiked AFB1 } \\
\text { level (ng/mL) }\end{array}$ & 0.02 & 0.05 & 0.1 & 0.2 & 0.4 & 0.5 \\
\hline $\begin{array}{c}\text { Measured level } \\
\text { (ng/mL) }\end{array}$ & 0.03 & 0.06 & 0.12 & 0.28 & 0.36 & $>0.4$ \\
\hline $\begin{array}{c}\text { Measured } \\
\text { optical density }\end{array}$ & 1.429 & 1.106 & 0.663 & 0.297 & 0.226 & 0.199 \\
\hline
\end{tabular}

These data, taken together, suggest that the wet milling procedure (slurry method associated with final dilution factor of 1247) had satisfactory robustness as demonstrated by suitable repeatability of extraction efficiency, while stability of extraction solvent in storage at ambient temperature for three months and good within-laboratory reproducibility indicated its acceptable ruggedness [52,54,76]. Good robustness and ruggedness indicate satisfactory stability of our improved aflatoxin test procedure.

\subsubsection{Evaluation of the Improved Aflatoxin Test Procedure}

The number of replicates of individual samples processed to achieve acceptable level of inter-assay precision (i.e., HorRat $\leq 1$ ) during analysis of 251 field-collected feed samples (routine analysis) is shown in Table 7. A left-skewed one-tailed distribution was observed, with the majority of the samples $(75 \%)$ adequately analyzed using paired test portions (recommended minimum number) with a further $20 \%$ requiring a third run, all these totaling to $95 \%$ of the samples. This indicates reduced cost due to sample re-testing in terms of resources and time, decreasing sample analysis turnaround time. Table 8 compares the characteristics of the novel aflatoxin testing procedure with those of other aflatoxin testing protocols recently used to collect aflatoxin residues data in chicken feed. Due to large uncertainty associated with estimation of dietary aflatoxin, FAO [59] has a sampling tool to guide workers on the size of laboratory and test portion samples. For granular products such as finished commercial animal feed, an aggregate sample of more than $2 \mathrm{~kg}$, laboratory sample of not less than $2 \mathrm{~kg}$ and test portion sample of at least $50 \mathrm{~g}(2 \times 25 \mathrm{~g})$ have to be processed to reduce results variability. Our modified aflatoxin test adheres to these criteria, while the other published methods fail to meet the appropriate aggregate sample, laboratory sample and/or test portion size (Table 8). Additionally, all of the published methods employed dry milling method for sample homogenization. Because solid-liquid extraction procedures are expensive, workers are tempted to use small test portion samples (which increase inherent variation). Our improved test incorporates a wet milling step (water slurring) in the extraction procedure. This allows processing of the recommended size of the test portion sample of $50 \mathrm{~g}$. Since wet milling is far more effective in sample homogenizing compared to dry milling, a small aliquot of homogenized slurry can be analyzed with minimal inherent variability $[35,39,43,61]$. For routine analysis, a minimum of two replicates was performed to achieve the required level of inter-assay precision of HorRat $\leq 1$ and replicates were increased until this was accomplished (Section 4.2.8). 
Table 7. Number of replicates ( $25 \mathrm{~g}$ test portions) required to attain acceptable level of precision during routine analysis of aflatoxin B1 in chicken feed employing the improved test procedure. Percentage of samples analyzed is included in brackets. Paired test portion (duplicate analysis) is the minimum number of replicates recommended by FAO Mycotoxin Sampling tool.

\begin{tabular}{cccccc}
\hline & \multicolumn{3}{c}{ Number of Replicates Required to Attain Acceptable Intra-Assay Precision } \\
\cline { 2 - 6 } & $\begin{array}{c}\text { Two Replicates } \\
\text { Required }\end{array}$ & $\begin{array}{c}\text { Three Replicates } \\
\text { Required }\end{array}$ & $\begin{array}{c}\text { Four Replicates } \\
\text { Required }\end{array}$ & $\begin{array}{c}\text { Five Replicates } \\
\text { Required }\end{array}$ & $\begin{array}{c}\text { Six Replicates } \\
\text { Required }\end{array}$ \\
\hline $\begin{array}{c}\text { Number and } \\
\text { percentage of }\end{array}$ & 188 & 51 & 8 & 2 & 2 \\
samples analyzed & $(74.9 \%)$ & $(20.3 \%)$ & $(3.2 \%)$ & $(0.8 \%)$ & $(0.8 \%)$ \\
\hline
\end{tabular}

Table 8. Sample homogenization techniques, size of aggregate, laboratory and test portion samples of various aflatoxin analysis protocols compared to the modified (novel) test procedure. This highlights compliance of our modified to FAO criteria for aflatoxin analysis.

\begin{tabular}{|c|c|c|c|c|c|}
\hline \multirow[b]{2}{*}{ Study Reference } & \multicolumn{5}{|c|}{ Characteristics of Aflatoxin Test Procedures } \\
\hline & $\begin{array}{l}\text { Homogenization } \\
\text { Method }\end{array}$ & $\begin{array}{c}\text { Aggregate Sample } \\
(\mathrm{kg})\end{array}$ & $\begin{array}{c}\text { Laboratory } \\
\text { Sample (kg) }\end{array}$ & $\begin{array}{l}\text { Size of Test } \\
\text { Portion }\end{array}$ & Analytical Method \\
\hline [15] & Dry milling & 4 & Not given & $5 \mathrm{~g}$ & LC-MS/MS \\
\hline [16] & Dry milling & $1-2$ & 1 & $5 \mathrm{~g}$ & ELISA \\
\hline [19] & Dry milling & 1 & 1 & $5 \mathrm{~g}$ & LC-MS/MS \\
\hline [32] & Dry milling & Not given & Not given & Not given & HPLC/ELISA \\
\hline [18] & Dry milling & Not given & Not given & $50 \mathrm{~g}$ & VICAM Fluorimeter \\
\hline [13] & Not given & Not given & Not given & Not given & Not given \\
\hline [14] & Not given & 1 & Not given & Not given & TLC \\
\hline Novel method & $\begin{array}{c}\text { Wet milling } \\
\text { (water slurring) }\end{array}$ & $>2$ & 2 & $\begin{array}{l}\text { at least } \\
25 \mathrm{~g} \times 2\end{array}$ & $\begin{array}{l}\text { ELISA or any other } \\
\text { quantification method }\end{array}$ \\
\hline
\end{tabular}

\section{Conclusions}

The in-house validation data presented here show that the improved aflatoxin test procedure is suitable for estimation of aflatoxin contamination levels in chicken feed. The optimal aflatoxin B1 extraction conditions are wet milling (water slurring $25 \mathrm{~g}$ feed in $37.5 \mathrm{~mL}$ water), solid-liquid extraction $1.3 \mathrm{~g}$ slurry (0.52 matrix: 0.78 water, $w / w)$ with acetonitrile:water $(80: 20, v / v)$ at dilution rate of slurry/acetonitrile solvent $(1: 66.5, w / v)$ followed by extraction back to aqueous phase at dilution rate of extract/phosphate buffered saline tween $20(1: 6.5, v / v)$. The improved aflatoxin test procedure is an accurate, precise, stable, reliable and cost-effective tool (in terms of time and resources) for surveillance of dietary aflatoxin. The improved aflatoxin test procedure described herein is especially suitable for laboratories that may not have access to automated sample-splitting equipment.

\section{Materials and Methods}

\subsection{Description of Improved Aflatoxin Test Procedure}

The improved aflatoxin test procedure for animal feed was designed using FAO mycotoxin sampling tool $[40,77]$ with modification. Briefly, sample selection made from a stationary lot to get a representative aggregate sample (primary sampling) was representatively mass reduced to a $2 \mathrm{~kg}$ laboratory sample (secondary sampling) and then two $25 \mathrm{~g}$ test samples (tertiary sampling) selected from $2 \mathrm{~kg}$ laboratory sample. The test samples were then homogenized by slurring in water, a $1.3 \mathrm{~g}$ analytical portion was removed from the analytical sample slurry material (quaternary sampling) and aflatoxin extracted in an 
organic solvent. The analyte was then extracted back to aqueous phase, phosphate buffered saline tween 20 (PBST) prior to analysis for AFB1 by competitive ELISA.

\subsubsection{Sample Selection (Primary Sampling)}

The number of bags (sub-lots) sampled was determined as described earlier [49]. Incremental samples (200 g each) were collected by random sampling [49,78] from as many locations of the lot as possible [54], thoroughly mixed to make an aggregate sample (of at least $2 \mathrm{~kg}$ ). If the number of containers (bags) was $\leq 10$ bags, all were sampled and, if $>10$ bags, every 4 th bag was sampled in every row. All units in the lot were made accessible. To collect incremental samples, a sampling cup was used for open containers (bags) after thorough mixing, while, for closed containers, a bag trier was used. Silica gel packs were added to the aggregate samples, double bagged in brown bags, transported to the laboratory and stored at $4{ }^{\circ} \mathrm{C}$ until required [54]. All aggregate samples should first be comminuted prior to mass reduction.

\subsubsection{Comminution and Mass Reduction of Samples (Secondary Sampling)}

Pellet and crumb aggregate feed samples (varying in size but at least $2 \mathrm{~kg}$ ) were first comminuted in a laboratory grinder (Grindomix Retsch ${ }^{\circledR}$ Model Gm 200, Hann, Germany) at a rotary speed of $10 \times 1000 \mathrm{RPM}$ for $30 \mathrm{~s}$ before mass reduction to laboratory samples. This was carried out in 330-350 g aggregate sample portions to protect the grinder from malfunctioning due to overheating. The comminuted aggregate feed samples were then representatively mass-reduced to $2 \mathrm{~kg}$ laboratory samples employing coning and quartering technique recommended for sample-splitting of feed samples $[49,60]$ and described earlier [57] but with modification. Briefly, the comminuted aggregate sample was mixed and shoveled into a cone, then flattened by pressing the top without further mixing and dividing the flat circular pile into equal quadrants. Two opposite portions were discarded while the remaining two opposite portions were mixed and shoveled into a cone and the procedure repeated until the material was reduced into four quadrants each of about $500 \mathrm{~g}$. Three quadrants were randomly selected, pooled and the mass topped up to $2 \mathrm{~kg}$ laboratory sample on an electronic weighing balance (Mettler PM34, DoltaRange ${ }^{\circledR}$, Zürich, Switzerland)by transferring many small portions randomly picked from the 4th quadrant and double bagged in fresh brown bags. The shoveling and coning process was carried out under a funnel fastened on a tripod stand to ensure uniform distribution of the material.

\subsubsection{Preparation of Test Portions (Tertiary Sampling)}

The $2 \mathrm{~kg}$ laboratory samples were split into four aliquots of about $31 \mathrm{~g}$. Briefly, the $2-\mathrm{kg}$ laboratory samples were representatively mass reduced through five runs of modified coning and quartering method described above until four quadrants each of between 30 $35 \mathrm{~g}$ were formed. Two $25 \mathrm{~g}$ test portions were weighed out from each of opposite portions and the alternate quadrants used for adjusting weights of the selected corresponding test portions if they were below the desired size of $25 \mathrm{~g}$.

\subsubsection{Sample Extraction (Quaternary Sampling)}

Before blending, dry-run of equipment was carried out to locate particulate contaminants and then cleaned with 70\% ethanol. Two (2) $25 \mathrm{~g}$ test portions were homogenized by a wet milling step through 2.5-fold dilution proposed earlier for maize samples [59], followed by high speed slurring in water. Briefly, a $25 \mathrm{~g}$ test portion was transferred to a kitchen blender cup, $37.5 \mathrm{~mL}$ water added (matrix/water ratio of 1:1.5, $w / v$ ) and blended at high speed (Moulinex ${ }^{\circledR}$, Model: Type LM240, Écully, France) for 5 min using a two-step milling protocol ( 3 min running; 1.5 min pulse; 2 min running) and $1.3 \mathrm{~g}$ slurry ( $0.52 \mathrm{~g}$ feed: $0.78 \mathrm{~g}$ water) immediately weighed out for extraction and quantification for AFB1. Regular tapping of the blending cup during blending was critical for successful sample homogenization. This reduced splashing of contents on sides of container away from the 
macerating rotor. Further, the slurry aliquot was weighed out immediately after slurring, directly to the bottom avoiding the neck of the extraction bottle. In each slurry sample, $86.5 \mathrm{~mL}$ of acetonitrile (HPLC Grade):water (Milli Q) $(80: 20, v / v)$ was added, contents agitated at $300 \mathrm{rpm}$ for $15 \mathrm{~min}$ in orbital shaker-incubator $\left(\mathrm{MRC}^{\circledR}\right.$, Model: Tou-50, Holon, Israel), allowed to settle for $40 \mathrm{~min}$ at ambient temperature, supernatant extract decanted and stored at $4{ }^{\circ} \mathrm{C}$.

\subsubsection{Quantification of AFB1 in Feed Samples}

The extract was prepared and analyzed for AFB1 using AFB1-ELISA low matrix kit (Helica Biosystems Inc. ${ }^{\circledR}$ ) according to manufacturer's instructions but with modification. Briefly, $100 \mu \mathrm{L}$ of the extract, appropriately diluted in phosphate buffered saline containing tween 20 (PBS-T) was loaded on polystyrene ELISA micro-plate with immobilized mouse anti-AFB1 monoclonal antibodies, incubated at ambient temperature for $30 \mathrm{~min}$, contents decanted and plate washed with PBS-T (this was prepared by dissolving contents of PBS-T packet in $1 \mathrm{~L}$ distilled water) to remove non-specific reactants, $100 \mu \mathrm{L}$ of AFB1-horseradish peroxidase conjugate added and incubated again for $30 \mathrm{~min}$, contents decanted and washed with PBS-T to remove non-specific reactants. Substrate-chromogen reagent $(100 \mu \mathrm{L})$ was added and incubated at ambient temperature for $10 \mathrm{~min}$ before stopping the reaction with $100 \mu \mathrm{L}$ of acid solution and the optical density (ODs), which is inversely proportional to aflatoxin concentration measured at $450 \mathrm{~nm}$ on a multi-channel micro-plate reader (BDSL Immunoskan Plus, Finland) inter-faced to a personal computer (Dell ${ }^{\circledR}$, Precision 470, Cherrywood, Ireland) and the OD s recorded using Eiaquik program (@ M.C Eisler, 1995). By setting the "zero" standard as $100 \%$ binding $\left(\mathrm{B}_{0}\right)$, percent binding for each standard and sample as a percent of the zero binding $\left(\% \mathrm{~B} / \mathrm{B}_{0}\right)$ was calculated. Average absorbance values for each standard and sample extract dilution $(B)$ and that of reagent blank $\left(B_{0}\right)$ were used to calculate percentage inhibition $\left(\mathrm{B} / \mathrm{B}_{0} \%\right)$ for each standard and sample dilution, and for construction of 4-parameter calibration curve (log of standard concentration versus logit of $\mathrm{B} / \mathrm{B}_{0} \%$ ) using programmed template spreadsheets (Microsoft Excel Office 1997-2003). The calibration curve was used to calculate AFB1 concentrations of unknown samples. For the conventional method (Groups VI and VIII), 80\% acetonitrile (ACN) extract to PBS-T ratio was 100:900, v/v., while for the novel method (Groups II and V) this was modified to 100:650, v/v (Table 2).

\subsection{In-House Validation of Improved Aflatoxin Test Procedure \\ 4.2.1. Materials}

Crystalline aflatoxin B1 (Fermentek Ltd., Jerusalem, Israel) was quantified on UV-Vis spectrophotometer (UV-1650 PC, Shimadzu ${ }^{\circledR}$, Kyoto, Japan) by scanning using spectrum mode against methanol blank, absorbance peaks read between 200 and $500 \mathrm{~nm}$ as described earlier [79]. Chicken feed specimens (mash form) collected from animal feed retail shops were analyzed for AFB1 using the aforementioned commercial ELISA kit. Specimens with AFB1 levels below the LOD were selected and pooled to make native pseudo blank material [80] for spiking and recovery, and replication studies, and determination of LOD and LOQ. The blank feed material was representatively split to the desired size of test portions employing coning and quartering method recommended for mass reduction of feed samples [49,60] and described earlier [57] with modification described above. AFB1 maize reference $(23 \mathrm{ppb})$ material was acquired from Biosciences eastern and central Africa-International Livestock Research Institute Hub (BecA-ILRI, Nairobi campus) for ruggedness studies.

\subsubsection{Study Design}

Completely randomized designs for spike and recovery and replication studies and determination of LOD and LOQ are shown in Table 2. There were 11 groups of native pseudo blank feed aliquots (Groupa I-XI) representatively split from the native pseudo blank feed material employing the modified coning and quartering method described 
above. In addition, 3 groups of acetonitrile extracts of feed aliquots (Groups XII-XIV) were used for LOD and LOQ studies. Five groups were used for spike and recovery studies. First, conventional dry milling (Group I) and our novel wet milling (Group II) procedure were compared (Table 2). Eighteen $25 \mathrm{~g}$ aliquots were randomly assigned to a $2 \times 3$ factorial arrangement i.e., 9 aliquots for each of the two milling methods and three aliquots randomly selected for spiking to achieve three levels of AFB1 (0, 20 or $100 \mathrm{ppb})$. The EU legal AFB1 residue limits in feed for adult poultry and young animals are 20 and $10 \mathrm{ppb}$ respectively $(\mathrm{EU}, 2002)$, but in tropical countries it is common to find feed naturally contaminated with $100 \mathrm{ppb}$ AFB1 and above $[13,15,18,19]$. Of the 9 aliquots assigned to each group, 3 sets each of 3 aliquots were randomly selected for either of the three AFB1 levels. Secondly, efficiency of various extraction conditions (sample: organic solvent ratio and organic solvent extract: PBST ratio) associated with wet milling procedure were compared. Forty-five $25 \mathrm{~g}$ aliquots were randomly assigned to a $3 \times 1$ factorial arrangement i.e., 15 aliquots for each of the three extraction conditions (Groups III-V) and five aliquots randomly selected for spiking to achieve either of the three levels of AFB1, 0, 20 or $100 \mathrm{ppb}$. The number of replicates for Groups I and II was therefore 6, and it was 10 for Groups III-V (Table 2). Dry milling procedure involving representative splitting of laboratory sample to obtain test portion, followed by solid-liquid extraction at dilution factor of approximately 5 (Group I) was considered here as the conventional method for recovery studies. The " 0 " ppb aliquots were used to determine baseline AFB1 levels and were therefore excluded in the sample size (Table 2).

The replication studies used 70 feed aliquots (10 $25 \mathrm{~g}$ aliquots analyzed whole; $225 \mathrm{~g}$ aliquots spilt to 20 wet $1.3 \mathrm{~g}$ aliquots; $125 \mathrm{~g}$ aliquot spilt to 10 dry $1.3 \mathrm{~g}$ aliquots; and $3025 \mathrm{~g}$ aliquots all spilt to 30 wet $1.3 \mathrm{~g}$ aliquots) divided into 6 groups (Table 2). For repeatability, 4 groups (Groups VI-IX) each of 10 feed aliquots were used in a $2 \times 3$ factorial arrangement to investigate which between dry and wet milling procedures had most suitable intralaboratory precision for secondary and tertiary sampling stages of sample mass reduction. In addition, intra-laboratory precision for 3 extraction conditions were also investigated. For intermediate precision work, 2 groups (Groups $\mathrm{X}$ and XI) each of 15 feed aliquots were used in a $5 \times 2 \times 3$ factorial design to investigate effect of analyst, extraction condition and time on measurement variability. The conventional method (dry milling conditions described in Table 2) for repeatability studies at secondary and tertiary sampling stages are represented by Groups VI and VIII, respectively. For LOD and LOQ determination, field collected feed specimens were screened for AFB1 and one with $8.9 \mathrm{ppb}$ (the lowest level) used as native pseudo blank material. Three groups of extracts derived from this material were used under three extraction conditions. Group XII (dry milling, final dilution factor $=1000)$ had 4 extracts while Groups XIII (dry milling, final dilution factor $=500$ ) and XIV (wet milling, final dilution factor $=1247$ ) each had 5 extracts. Dry milling procedures (Groups XII and XIII) represent the conventional method (Table 2).

\subsubsection{Aflatoxin Spike and Recovery Studies}

The solution of AFB1 (Fermentek Ltd., Jerusalem, Israel) in methanol (HPLC Grade) was spiked to achieve 20 or $100 \mathrm{ppb}$ AFB1 level, respectively, in $25 \mathrm{~g}$ native pseudo blank feed aliquots, while blank methanol was added to native pseudo blank feed aliquots designated as " $0 \mathrm{ppb}^{\text {". }}$

Comparison of Conventional (Dry) and Novel Water Slurry (Wet) Milling Procedure

To a $25 \mathrm{~g}$ feed aliquot, $1 \mathrm{~mL}$ blank methanol (HPLC Grade), $1 \mathrm{~mL}$ of 0.5 or $2.5 \mu \mathrm{g}$ AFB $1 / \mathrm{mL}$ solution in methanol (HPLC Grade) was spiked to achieve 0, 20 or $100 \mathrm{ppb}$ AFB1 level, respectively. Group I aliquots were blended in a kitchen blender (Moulinex ${ }^{\circledR}$, Model: Type LM240, Écully, France) at high speed for $1 \mathrm{~min}$, while Group II aliquots were prepared by adding $37.5 \mathrm{~mL}$ of water (2.5-fold dilution) and blending as described above (Section 4.1.4), and $2 \mathrm{~g}$ slurry immediately weighed out. To each of the $25 \mathrm{~g}$ dry and $2 \mathrm{~g}$ slurry samples, $133 \mathrm{~mL}$ acetonitrile:water $(80: 20, v / v)$ was added and the mixture agitated 
as described above (Section 4.1.4). Extracts of dry- and wet-blended aliquots were diluted 94.3-fold (final dilution factor $=500$ ) and 7.5-fold (final dilution factor $=1247$ ), respectively, in PBS-T and analyzed for AFB1 by ELISA as described above.

Comparison of Different Extraction Conditions Associated with Wet Milling Procedure

The $25 \mathrm{~g}$ aliquots were water-slurried and paired $1.3 \mathrm{~g}$ slurry analytical samples weighed out as described above (Section 4.1.4). To each of the $1.3 \mathrm{~g}$ slurry analytical sample, $130 \mathrm{~mL}$ acetonitrile water $(80: 20, v / v)$ was added for Group III (dilution factor $=100$ ), $65 \mathrm{~mL}$ acetonitrile:water $(80: 20, v / v)$ for Group IV (dilution factor $=50$ ) and $86.5 \mathrm{~mL}$ acetonitrile:water $(80: 20)$ was added Group V (dilution factor $=66.5)$, and the mixture was agitated as described in Section 4.1.4. The extracts were diluted 10-fold for Groups III (total dilution factor $=2500$ ) and IV (final dilution factor $=1250$ ) and 7.5-fold for Group $\mathrm{V}$ (final dilution factor $=1247$ ) in PBST. The extracts were analyzed for AFB1 by ELISA (Section 4.1.5) and the results of paired test portions for each slurry sample averaged. Mean background level was calculated, subtracted from each of the AFB1 levels of " 20 and $100 \mathrm{ppb}^{\prime \prime}$ replicates and these results expressed as percent recovery. For each group (Groups I-V), mean percent recovery, StDev and RSD of the replicates were calculated. Outlier values in the percent recovery data were identified on Excel 2013 using the following formula:

$$
\text { 1st quartile-1.5 IQR } \leq x \geq \text { 3rd quartile + 1.5 IQR }
$$

where $\mathrm{IQR}$ is the interquartile range.

Outlier identification criterion also included recommended mean recovery range of $75-125 \%$ by European Commission and variance predicted by the modified Horwitz equation $[50-53,63]$. Where more than one out of five replicates were identified as outliers, the data were discarded and spiking and recovery procedure repeated $[52,53]$.

\subsubsection{Replication Studies}

Representativeness of mass reducing methods was investigated as described earlier $[48,51,52,63,81]$.

Estimation of Intra-Laboratory Variability (Repeatability)

Ten $25 \mathrm{~g}$ test portions were extracted whole while the 11th one (from the same laboratory sample), was water-slurried (Section 4.1.4) and ten $1.3 \mathrm{~g}$ slurry aliquots weighed out for extraction. To each of the $25 \mathrm{~g}$ of dry (Group VI) and $1.3 \mathrm{~g}$ slurry (Group VII) aliquots, $130 \mathrm{~mL}$ acetonitrile:water $(80: 20, v / v)$ were added and the mixture agitated (Section 4.1.4), extracts diluted 10-fold in PBST and analyzed for AFB1 by ELISA (Section 4.1.5) to compare variance associated with the dry and wet milling methods at secondary sampling level. Intra-laboratory precision of two procedures was further investigated at tertiary sampling stage. Feed material $(50 \mathrm{~g})$ was representatively split into four equal portions by coning and quartering method (Section 4.1.2) and two opposite quadrants pooled to make two equal portions each weighing $25 \mathrm{~g}$. One portion was further split by two runs of 16 aliquots each weighing approximately $1.56 \mathrm{~g}$ from which 10 were randomly selected, dry $1.3 \mathrm{~g}$ analytical samples weighed (Group VIII) while the other $25 \mathrm{~g}$ portion was water slurried and ten $1.3 \mathrm{~g}$ slurry aliquots weighed (Group IX). Both dry and slurry samples were extracted and analyzed for AFB1 as described above.

Estimation of Intermediate Variability Associated with Wet Milling Procedure

Intermediate precision of the wet milling (slurry) method was also investigated. Five analysts were first trained, each randomly assigned three $25 \mathrm{~g}$ native pseudo blank feed aliquots, and each prepared a water slurry daily from one aliquot and weighed out one $1.3 \mathrm{~g}$ analytical sample as described above on three consecutive days. Each analytical sample was diluted 100-fold in acetonitrile:water (80:20, $v / v)$, mixture agitated (Section 4.1.4), extracts diluted 10-fold in PBST and analyzed for AFB1 by ELISA as described above (Group X). This was repeated with another set of fifteen $25 \mathrm{~g}$ test portions, but each slurry aliquot was 
diluted 66.5-fold in extraction solvent, agitated, diluted 7.5-fold in PBST and analyzed for AFB1 (Group XI).

\subsubsection{Determination of Limits of Detection (LOD) and Quantification (LOQ)}

To counteract matrix effect of chicken feed, we used blank measurement approach to determine LOD and LOQ [81,82]. Briefly a blank specimen was quantified for AFB1 in five measurements and mean OD value and standard deviation obtained. From this, an OD value of mean OD minus 2 standard deviations and mean OD minus 5 standard deviations were calculated to get two OD values which were extrapolated from the standard curve to get LOD and LOQ respectively. Details are given below. Two acetonitrile extracts of the blank specimen prepared by conventional dry milling procedure were pooled, then diluted 100-fold in PBST to attain baseline level of analyte signal and used for LOD and LOQ determination at two assay conditions. Six $100 \mu \mathrm{L}$ extract aliquots were diluted 100-fold in PBST (Group XII), while the other five $100 \mu \mathrm{L}$ aliquots were first diluted 5-fold in acetonitrile:water $(80: 20, v / v)$ and then 10-fold in PBS-T (for Group XIII). All the aliquots were further diluted 10-fold in PBST to attain final dilution factor of 1000 for Group XII and 500 for Group XIII for dry milling procedure, before analysis by ELISA. For wet milling procedure, five $25 \mathrm{~g}$ fresh feed aliquots were separately water slurried and blended, two $1.3 \mathrm{~g}$ analytical portions from each water slurry, weighed and diluted 66.5-fold in acetonitrile:water $(80: 20, v / v)$, contents agitated and extract harvested (Section 4.1.4). The extract was further diluted 66.5-fold in PBS-T to attain baseline level of analyte signal, then diluted 7.5-fold in PBS-T and assayed by ELISA to give a final dilution factor of 1247 (Group XIV) for wet milling procedure. The limit values were calculated from mean absorbance of the 0-standard, $\mathrm{B}_{0}$ [63] minus 2-fold (for LOD) and 5-fold (for LOQ) the StDev of absorbance [81] of replicate wells of the blank samples analyzed by ELISA. The means of the concentrations corresponding to the $\% \mathrm{~B} / \mathrm{B}_{0}$ value of $\mathrm{B}_{0}$ minus 2 -fold, and 5 -fold the standard deviation generated from the calibration curve was taken as the lowest detectable (LOD) and quantifiable (LOQ) concentration of AFB1.

\subsubsection{Linearity Studies}

Using pure crystalline AFB1 (Fermentek Ltd., Jerusalem, Israel), 0.5, 0.4, 0.2, 0.1, 0.05 and $0.02 \mathrm{ng} / \mathrm{mL}$ AFB1 standards in 80\% acetonitrile (HPLC Grade):water (Milli Q) (80:20):PBS-T mixture (10:65) were prepared, analyzed by AFB1-ELISA and the optical density (ODs) of duplicate wells read, as described in Section 4.1.5.

\subsubsection{Robustness and Ruggedness Studies}

We tested stability of our modified aflatoxin test procedure by examining influence of external factors on its most vulnerable performance parameters [51], precision and accuracy. Intra-laboratory repeatability was used to measure robustness while relatively long-term parameters such as intra-laboratory reproducibility and effect of storage time on extraction efficiency of extraction solvent measured of ruggedness. Determination of robustness was carried out by calculation of repeatability of surrogate recovery (Section 4.2.3). For ruggedness, intra-laboratory reproducibility (effects of day of analysis and analyst) was calculated (Section 4.2.4). Further, the effect of storage on extraction efficiency of organic solvent was investigated. Fresh acetonitrile:water $(80: 20, v / v)$ extraction solvent was prepared and divided into three batches; $1^{\text {st }}$ batch was used immediately, while 2 nd and 3 rd batches were stored at ambient temperature (minimum $=9.4 \pm 1.7^{\circ} \mathrm{C}$; maximum $=25.1 \pm 2.9^{\circ} \mathrm{C}$ ) for one and three months, respectively, prior to use. One gram of $23 \mathrm{ppb}$ maize reference specimen was extracted with $5 \mathrm{~mL}$ solvent by agitating and extract harvested (Section 4.1.4), analyzed for AFB1 (Section 4.1.5) and percent recoveries calculated.

\subsubsection{Evaluation of the Improved Aflatoxin Test Procedure}

In total, 251 chicken feed samples were collected in the field (one sample per lot) as described in Section 4.1.1, prepared and analyzed. Using a programmed spreadsheet 
(Microsoft Excel Office), minimum requirement criterion for variability associated with sample preparation and analysis was incorporated as a quality control measure. Interassay variance associated with sample analysis was evaluated as described earlier [56]. Observed inter-sample variance, observed relative standard deviation (RSD) associated with measurement of paired test portions of each laboratory sample was compared with the predicted relative standard deviation (PRSD) to give a Horwitz Ratio (HorRat) value; thus, HorRat value $=\mathrm{RSD}_{\mathrm{O}} / \mathrm{RSD}_{\mathrm{p}}$, where $\mathrm{RSD}_{\mathrm{O}}$ and $\mathrm{RSD}_{\mathrm{p}}$ are the observed RSD and PRSD, respectively. PRSD was calculated from the modified Horwitz equation which gives RSD as a function of analyte concentration [50-54]: RSD $<2^{(1-0.5 \log C)} \times 0.67$, where $C$ is the AFB1 concentration. For samples with HorRat values above 1 and AFB1 levels exceeding the regulatory limit for feed for animal feed $(20 \mathrm{ppb})$, fresh test portions were re-tested until HorRat value of $\leq 1$ was achieved [56]. However, all results from the same sample were averaged to give final mean result and none were discarded. Replicates per sample were recorded and the percent of samples analyzed using 2-6 replicates computed.

\subsection{Statistical Analysis}

Descriptive and inferential data analyses were done on statistical computer program (IBM SPSS Statistics 20). For spiking and recovery data, bias was calculated accordingly: $\%$ bias $=$ mean $\%$ recovery -100 . AFB1 recovery of the conventional dry milling procedure and the novel slurry method were analyzed by comparing means of Groups I and II employing independent $t$-test. Variability expressed as variance, standard deviation and coefficient of variation (relative standard deviation) for Groups I and II were computed and compared. Means of all wet milling procedures recovery data (Groups III-V) were compared employing Welch ANOVA to determine between and within the group variation. Games-Howell test (a post-hoc test) incorporated for multiple comparison of the groups. For spiking and recovery studies, RSD (or CV) effect were determined accordingly,

$$
\mathrm{E}_{\mathrm{CV}}=\mathrm{G}_{\mathrm{CV}}-\mathrm{M}_{\mathrm{CV}}
$$

where $\mathrm{E}_{\mathrm{CV}}=\mathrm{CV}$ effect, $\mathrm{G}_{\mathrm{CV}}=$ Group $\mathrm{CV}$ and $\mathrm{M}_{\mathrm{CV}}=$ Grand mean $\mathrm{CV}$

The extraction methods ranked according to $\mathrm{CV}$ effect values. HorRat values and ORSD/PRSD were used in replication studies to rank sample splitting procedures. For repeatability data, PRSD values were calculated from modified Horwitz equation of PRSD $<2^{(1-0.5 \log C)} \times 0.67$, while, for intermediate precision (within-laboratory reproducibility), PRSD was calculated from the unmodified Horwitz equation: PRSD $<2^{(1-0.5 \log C)}$, where $\mathrm{C}$ is the concentration of the analyte. The intermediate precision data (from replication studies) were further subjected to one-way ANOVA to determine whether the day of analysis and the analyst affected the data. For LOD and LOQ data, outlier OD values were identified using the unmodified Horwitz equation: $\mathrm{RSD}<2^{(1-0.5 \log C)}$ where, $\mathrm{C}$ is the aflatoxin concentration. OD values above $\mathrm{B}_{0}$ were also treated as outliers. The HorRat value associated with efficiency of extraction solvent of different shelf ages was used to evaluate variability due to solvent storage time.

Supplementary Materials: The following are available online at https:/ / www.mdpi.com/2072-665 1/13/3/216/s1, Dataset S1. Aflatoxin recovery data, Dataset S2. Precision data, Dataset S3. LOD and LOQ data, Dataset S4. Robustness-ruggedness data.

Author Contributions: Conceptualization, J.K., T.W., R.M., J.F.L. and D.G.; Data curation, J.K.; Formal Analysis, J.K., J.F.L. and R.M.; Funding acquisition, D.G., J.F.L., J.K. and L.M.; Investigation, J.K., R.M., T.W., D.M. and L.M.; Methodology, J.K., R.M., T.W. and T.P.H.; Project administration, J.K.; Resources, J.K., T.W. and T.P.H., Supervision, J.K. and R.M.; Visualization, J.K.; Writing-original draft, J.K.; and Writing—review and editing, T.W., J.F.L., L.M., T.P.H., R.M., D.G., D.M. and J.K. All authors have read and agreed to the published version of the manuscript.

Funding: This research was funded by Consultative Group on International Agricultural Research (CGIAR)-Research Program (https:/ / www.cgiar.org/research; accessed on 12 March 2021), Agriculture for Nutrition and Health (CRA between ILRI and KALRO Ref. Contract No. 1/2014) 
and Government of Kenya through Kenya Agricultural \& Livestock Research Organization (http: / / www.kalro.org; accessed on 12 March 2021). The APC was funded by CGIAR.

Institutional Review Board Statement: Not applicable.

Informed Consent Statement: Not applicable.

Data Availability Statement: The data presented in this study are available as supplementary material (Dataset S1. Aflatoxin recovery data; Dataset S2. Precision data; Dataset S3. LOD and LOQ data; Dataset S4. Robustness-ruggedness data).

Acknowledgments: This study was funded by CGIAR Research Program, Agriculture for Nutrition and Health (CRA between ILRI and KALRO Ref. Contract No. 1/2014) and the Government of Kenya (through KALRO) whom we sincerely thank. Former Director, Biotechnology Research Institute (BioRI) Sylvance Okoth is appreciated for his support and permission to carry out this work at KALRO-BioRI, Muguga. We acknowledge Andrew Slate (posthumously) of North Carolina State University, and Aloo of Public Health Laboratory(Kenyatta Hospital Complex, Nairobi) for their technical assistance. KALRO staff (Ben Wanyonyi, George Maina, Andrew Mageto, Gilbert Ouma, Sarah Kairuthi, Jackline Kagendo, Jacqueline Arusei, Agnes Nekesa, Mercyline Ong'ale and Clarah Jebet) also provided technical expertise while David Kinoti and M/s Joanna Auma (KALRO) provided statistical and bibliography softwares respectively. Phyllis Alusi of illustration unit KALRO, formatted the graphical abstract of this article. David Gikungu, the Deputy Director, Climate Services of the Kenya Metrological Department provided room temperature data for laboratory 5 (BioRI) for the period when this work was carried out. A former science teacher, Robert S. I. Karuku is highly acknowledged posthumously for inspiring the first author to the world of food poisoning, the main drive in this communication.

Conflicts of Interest: The authors declare no conflict of interest. TH is an employee of the manufacturer of aflatoxin diagnostic kit used in this study.

\section{References}

1. Oloo, R.G.; Okoth, S.; Wachira, P.; Mutiga, S.; Ochieng, P.; Kago, L.; Nganga, F.; Entfellner, J.B.D.; Ghimire, S. Genetic profiling of aspergillus isolates with varying aflatoxin production potential from different maize-growing regions of Kenya. Toxins 2019, 11, 467. [CrossRef]

2. Benkerroum, N. Aflatoxins: Producing-molds, structure, health issues and incidence in Southeast Asian and Sub-Saharan African Countries. Int. J. Environ. Res. Public Health 2020, 17, 1215. [CrossRef] [PubMed]

3. Kumar, P.; Mahato, D.K.; Kamle, M.; Mohanta, T.K.; Kang, S.G. Aflatoxins: A global concern for food safety, human health and their management. Front. Microbiol. 2017, 7, 2170. [CrossRef] [PubMed]

4. Pereira, C.S.; Sara, C.C.; Fernandes, J.O. Prevalent mycotoxins in animal feed: Occurrence and analytical methods. Toxins 2019, 11, 290. [CrossRef] [PubMed]

5. World Health Organization. Aflatoxins; REF. No.: WHO/NHM/FOS/RAM/18.1; World Health Organization: Geneva, Switzerland, 2018.

6. World Health Organization; International Agency for Research on Cancer. IARC monographs on the evaluation of carcinogenic risks to humans. In Some Traditional Herbal Medicines, Some Mycotoxins, Naphthalene and Styrene; World Health Organization/International Agency for Research on Cancer: Lyon, France, 2002; Volume 82, pp. 1-590.

7. Carballo, D.; Font, G.; Ferrer, E.; Berrada, H. Evaluation of mycotoxin residues on ready-to-eat food by chromatographic methods coupled to mass spectrometry in tandem. Toxins 2018, 10, 243. [CrossRef] [PubMed]

8. Alshannaq, A.; Yu, J.-H. Occurrence, toxicity, and analysis of major mycotoxins in food. Int. J. Environ. Res. Public Health 2017, 14, 632. [CrossRef]

9. Peraica, M.; Radic, B.; Lucic, A.; Pavlovic, M. Toxic effects of mycotoxins in humans. Bull. World Health Organ. 1999, 77, 754-766. [PubMed]

10. Probst, C.; Njapau, H.; Cotty, P.J. Outbreak of an acute aflatoxicosis in Kenya in 2004: Identification of the causal agent. Appl. Environ. Microbiol. 2007, 73, 2762-2764. [CrossRef] [PubMed]

11. Grace, D.; Kang'ethe, E.; Lindahl, J.; Atherstone, C.; Wesonga, T. Aflatoxin: Impact on Animal Health and Productivity. Building an Aflatoxin Safe East African Community—Technical Policy Paper 4; IITA: Dar es Salam, Tanzania, 2015.

12. Suleiman, E.A.; Elgabbar, M.A.; Khaliefa, K.A.; Omer, F.A. Aflatoxins in broiler chicks feed. Sudan J. Vet. Res. 2010, 25, 5-8.

13. Banday, M.T.; Darzi, M.M.; Khan, A.A. Clinico-pathological and haemo-biochemical changes in broiler chicken following an outbreak of aflatoxicosis. Appl. Biol. Res. 2006, 8, 40-43.

14. Rashid, N.; Bajwa, M.A.; Rafeeq, M.; Khan, M.A.; Ahmad, Z.; Tariq, M.M.; Wadood, A.; Abbas, F. Prevalence of aflatoxin B1 in finished commercial broiler feed from west central Pakistan. J. Anim. Plant. Sci. 2012, 22, 6-10. 
15. Akinmusire, O.O.; El-Yuguda, A.-D.; Musa, J.A.; Oyedele, O.A.; Sulyok, M.; Somorin, Y.M.; Ezekiel, C.N.; Krska, R. Mycotoxins in poultry feed and feed ingredients in Nigeria. Mycotoxin Res. 2019, 35, 149-155. [CrossRef]

16. Greco, M.V.; Franchi, M.L.; Golba, S.L.R.; Pardo, A.G.; Pose, G.N. Mycotoxins and mycotoxigenic fungi in poultry feed for food-producing animals. Sci. World J. 2014, 2014, 1-9. [CrossRef] [PubMed]

17. Gathumbi, J.K.; Bebora, L.C.; Muchiri, D.J.; Ngatia, T.A. A survey of mycotoxins in poultry feeds used in Nairobi, Kenya. Bull. Anim. Health Prod. Afr. 1995, 43, 243-245.

18. Nakavuma, J.; Kirabo, A.; Bogere, P.; Nabulime, M.M.; Kaaya, A.N.; Gnonlonfin, B. Awareness of mycotoxins and occurrence of aflatoxins in poultry feeds and feed ingredients in selected regions of Uganda. Int. J. Food Contam. 2020, 7, 1-10. [CrossRef]

19. Kemboi, D.C.; Ochieng, P.E.; Antonissen, G.; Croubels, S.; Scippo, M.-L.; Okoth, S.; Kangethe, E.K.; Faas, J.; Doupovec, B.; Lindahl, J.F.; et al. Multi-mycotoxin occurrence in dairy cattle and poultry feeds and feed ingredients from Machakos town, Kenya. Toxins 2020, 12, 762. [CrossRef] [PubMed]

20. FAO. Worldwide Regulations for Mycotoxins in Food and Feeds in 2003. FAO Food and Nutrition Paper 81. Available online: http: / / www.fao.org/3/y5499e/y5499e02.htm (accessed on 14 February 2021).

21. FDA. Guidance for Industry: Action Levels for Poisonous or Deleterious Substances in Human Food and Animal Feed; US Department of Health and Human Services, US Food and Drugs Administration: Washington, DC, USA, 2017; Volume 2018.

22. EU. Commission regulation (EU) No 165/2010 of 26 February 2010. Off. J. Eur. Union 2010, 50, 8-12.

23. EC. Directive 2002/32/EC of the European parliament and of the council of 7 may 2002 on undesirable substances in animal feed. Off. J. Eur. Communities 2002, 140, 110-121.

24. Tang, L.; Xu, L.; Afriyie-Gyawu, E.; Liu, W.; Wang, P.; Tang, Y.; Wang, Z.; Huebner, H.J.; Ankrah, N.A.; Ofori-Adjei, D.; et al. Aflatoxin-albumin adducts and correlation with decreased serum levels of vitamins A and $\mathrm{E}$ in an adult Ghanaian population. Food Addit. Contam. Part. A 2009, 26, 108-118. [CrossRef] [PubMed]

25. Williams, J.H.; Phillips, T.D.; Jolly, P.E.; Stiles, J.K.; Jolly, C.M.; Aggarwal, D. Human aflatoxicosis in developing countries: A review of toxicology, exposure, potential health consequences and interventions. Am. J. Clin. Nutr. 2004, 80, 1106-1122. [CrossRef] [PubMed]

26. Amin, Y.A.; Mohamed, R.H.; Zakaria, A.M.; Wehrend, A.; Hussein, H.A. Effects of aflatoxins on some reproductive hormones and composition of buffalo's milk. Comp. Clin. Pathol. 2019, 28, 1191-1196. [CrossRef]

27. El Mahady, M.M.; Ahmed, K.A.; Badawy, S.A.; Ahmed, Y.F.; Aly, M.A. Pathological and hormonal effects of aflatoxins on reproduction of female albino rats. Middle East. J. Appl. Sci. 2015, 5, 998-1006.

28. Umar, S.; Younus, M.; Rehman, M.U.; Aslam, A.; Shah, M.A.A.; Munir, T.; Hussain, S.; Iqbal, F.; Fiaz, M.; Ullah, S. Role of aflatoxin toxicity on transmissibility and pathogenicity of H9N2 avian influenza virus in turkeys. Avian Pathol. 2015, 44, 305-310. [CrossRef] [PubMed]

29. Trench, P.C.; Narrod, C.; Roy, D.; Tiongco, M. Responding to health risks along the value chain. 2020 Conference Paper 5. In Proceedings of the Leveraging Agriculture for Improving Nutrition and Health, New Delhi, India, 10-12 February 2011; pp. 1-54

30. Fouad, A.M.; Ruan, D.; El-Senousey, H.K.; Chen, W.; Jiang, S.; Zheng, C. Harmful effects and control strategies of aflatoxin B1 produced by Aspergillus flavus and Aspergillus parasiticus strains on Poultry: Review. Toxins 2019, 11, 176. [CrossRef] [PubMed]

31. Andretta, I.; Kipper, M.; Lehnen, C.R.; Hauschild, L.; Vale, M.M.; Lovatto, P.A. Meta-analytical study of productive and nutritional interactions of mycotoxins in broilers. Poult. Sci. 2011, 90, 1934-1940. [CrossRef] [PubMed]

32. Morrison, D.M.; Ledoux, D.R.; Chester, L.F.B.; Samuels, C.A.N. A limited survey of aflatoxins in poultry feed and feed ingredients in Guyana. Vet. Sci. 2017, 2017, 60. [CrossRef]

33. Bata-Vidács, I.; Kosztik, J.; Mörtl, M.; Székács, A.; Kukolya, J. Aflatoxin B1 and sterigmatocystin binding potential of nonLactobacillus LAB Strains. Toxins 2020, 2020, 799. [CrossRef]

34. Kosztik, J.; Mörtl, M.; Székács, A.; Kukolya, J.; Bata-Vidács, I. Aflatoxin B1 and sterigmatocystin binding potential of lactobacilli. Toxins 2020, 2020, 756. [CrossRef]

35. Ozer, H.; Basegmez, H.O.; Whitaker, T.B.; Slate, A.B.; Giesbrecht, F.G. Sampling dried figs for aflatoxin-Part 1: Variability associated with sampling, sample preparation, and analysis. World Mycotoxin J. 2017, 10, 31-40. [CrossRef]

36. Grace, D.; Lindahl, J.; Atherstone, C.; Kang'ethe, E.; Nelson, F.; Wesonga, T.; Manyong, V. Aflatoxin standards for feed. In Building an Aflatoxin Safe East African Community—Technical Policy Paper 7; IITA: Dar es Salam, Tanzania, 2015.

37. Whitaker, T.B. Sampling foods for mycotoxins. Food Addit. Contam. 2006, 23, 50-61. [CrossRef]

38. Matumba, L.; Whitaker, T.; Slate, A.; De Saeger, S. Current trends in sample size in mycotoxin in grains. Are we measuring accurately? Toxins 2017, 9, 276.

39. Cheli, F.; Campagnoli, A.; Pinotti, P.; Fusi, E.; Dell'Orto, V. Sampling feed for mycotoxins: Acquiring knowledge from food. Ital. J. Anim. Sci. 2009, 8, 5-22. [CrossRef]

40. Food and Agriculture Organization of the United Nations. Mycotoxin Sampling Tool. User Guide. Version 1.0 (December 2013), Version 1.1 ed.; Food and Agriculture Organization of the United Nations: Rome, Italy, 2013; p. 62.

41. Whitaker, T.B.; Slate, A.B. Comparing the USDA/AMS subsampling mill to a vertical cutter mixer type mill used to comminute shelled peanut samples for aflatoxin analysis. Peanut Sci. 2012, 39, 69-81. [CrossRef]

42. Kumphanda, J.; Matumba, L.; Whitaker, T.B.; Kasapila, W.; Sandahl, J. Maize meal slurry mixing: An economical recipe for precise aflatoxin quantitation. World Mycotoxin J. 2019, 12, 203-212. [CrossRef] 
43. Oulkar, D.; Goon, A.; Dhanshetty, M.; Khan, Z.; Satav, S.; Banerjee, K. High-sensitivity direct analysis of aflatoxins in peanuts and cereal matrices by ultra-performance liquid chromatography with fluorescence detection involving a large volume flow cell. $J$. Environ. Sci. Health Part B 2018, 53, 255-260. [CrossRef] [PubMed]

44. Okuma, T.A.; Huynh, T.P.; Hellberg, R. Use of Enzyme-linked immunosorbent assay to screen for aflatoxins, ochratoxin A, and deoxynivalenol in dry pet foods. Mycotoxin Res. 2018, 34, 69-75. [CrossRef] [PubMed]

45. Taye, W.; Ayalew, A.; Chala, A.; Dejene, M. Aflatoxin B1 and total fumonisin contamination and their producing fungi in fresh and stored sorghum grain in East Hararghe, Ethiopia. Food Addit. Contam. Part B 2016, 9, 237-245. [CrossRef] [PubMed]

46. Nguyen, X.T.T.; Nguyen, T.T.T.; Nguyen-Viet, H.; Tran, K.N.; Lindahl, J.; Randolph, D.G.; Ha, T.M.; Lee, H.S. Assessment of aflatoxin B1 in maize and awareness of aflatoxins in Son La, Vietnam. Infect. Ecol. Epidemiol. 2018, 8. [CrossRef]

47. Huynh, T.P.; Ly, C. Recovery of aflatoxin B1 in a range of food commodities utilizing a matrix resistant ELISA. In Proceedings of the IAFP 2015 Annual Meeting, Portland, OR, USA, 25-28 July 2015.

48. Wagner, C. Critical practicalities in sampling for mycotoxins in feed. J. Aoac Int. 2015, 98, 301-308. [CrossRef]

49. Herrman, T. Sampling: Procedures for feed. MF-2036. Feed Manufacturing. Kansas State University Agricultural Experiment Station and Cooperative Extension Service: 2001. Department of Grain Science. Available online: http://www.oznet.ksu.edu/ library/grsci2/MF2036 (accessed on 23 January 2014).

50. Rao, T.N. Validation of Analytical Methods; IntechOpen: London, UK, 2018; Chapter 7. [CrossRef]

51. BPU. Guidelines for Validation of Analytical Methods for Non-Agricultural Pesticide Active Ingredients and Products. Available online: www.hse.gov.uk/biocides/copr/pdfs/validation. (accessed on 14 October 2016).

52. EC. Technical Material and Preparations: Guidance for Generating and Reporting Methods of Analysis in Support of Pre- and Post-Registration Data Requirements for Annex II (Part A, Section 4) and Annex III (Part A, Section 5) of Directive 91/414. Available online: https:/ / ec.europa.eu/food/sites/food/files/plant/docs/pesticides_ppp_app-proc_guide_phys-chem-ana_ tech-mat-preps.pdf (accessed on 14 October 2016).

53. OECD. Guidance document for single laboratory validation of quantitative analytical methods-guidance used in support of preand-post-registration data requirements for plant protection and biocidal products. In Environment, Health and Safety Publications Series on Testing and Assessment; No. 204 and Series on Biocides No. 9. ENV/JM/MONO (2014) 20; Organisation for Economic Co-operation and Development: Paris, France, 2014; Volume JT03360406.

54. EC. Laying down the methods of sampling and analysis for the official control of the levels of mycotoxins in foodstuffs. Off. J. Eur. Union 2006, 70, 12-33.

55. EU. Commission recommendation of 17 August 2006 on the presence of deoxynivalenol, zearalenone, ochratoxin A, T-2 and HT-2 and fumonisins in products intended for animal feeding. Off. J. Eur. Union 2006, 229, 227-229.

56. Dragacci, S.; Grosso, F. Validation of Analytical Methods to Determine the Content of Aflatoxin, Ochratoxin and Patulin in Foodstuffs of Vegetable Origin; European Commission BCR Information Chemical Analysis: Paris, France, 1999; pp. 1-40.

57. Gerlach, R.W.; Dobb, D.E.; Raab, G.A.; Nocerino, J.M. Gy sampling theories in environmental studies. 1. Assessing soil splitting protocols. J. Chemom. 2002, 16, 321-328. [CrossRef]

58. Walker, M.; Colwell, P.; Cowen, S.; Ellison, S.L.R.; Gray, K.; Elahi, S.; Farnell, P.; Slack, P.; Burns, D.T. Aflatoxins in GroundnutsAssessment of the effectiveness of EU sampling and UK enforcement sample preparation procedures. J. Assoc. Public Anal. 2017, $45,1-22$.

59. Food and Agriculture Organization of the United Nations. Sampling Plans for Aflatoxin Analysis in Peanuts and Corn. FAO Food and Nutrition Paper 55. Report of an FAO Technical Consultation Rome; Food and Agriculture Organization of the United Nations: Rome, Italy, 1993.

60. Reiter, E.V.; Dutton, M.F.; Agus, A.; Nordkvist, E.; Mwanza, M.F.; Njobeh, P.B.; Prawano, D.; Haggblom, P.; Razzazi-Fazeli, E.; Zentek, J.; et al. Uncertainty from sampling in measurement of aflatoxins in animal feedstuffs: Application of the Eurachem/CITAC guidelines. Analyst 2011, 136, 4059-4069. [CrossRef] [PubMed]

61. Spanjer, M.C.; Scholten, J.M.; Kastrup, S.; Jorissen, U.; Schatzki, T.F.; Toyofuku, N. Sample comminution for mycotoxin analysis: Dry milling or slurry mixing? Food Addit. Contam. 2006, 23, 73-83. [CrossRef]

62. IUPAC. Harmonized guidelines for single laboratory validation of methods of analysis. IUPAC Technical Report. Pure Appl. Chem. 2002, 74, 835-855. [CrossRef]

63. APVMA. Guidelines for the Validation of Analytical Methods for Active Constituent, Agricultural and Veterinary Chemical Products. Available online: http:/ / www.apvma.gov.au (accessed on 14 October 2016).

64. Shao, D.; Imerman, P.M.; Schrunk, D.E.; Ensley, S.M.; Rumbeiha, W.K. Intralaboratory development and evaluation of a highperformance liquid chromatography-fluorescence method for detection and quantitation of aflatoxins M1, B1, B2, G1, and G2 in animal liver. J. Vet. Diagn. Investig. 2016, 28, 646-655. [CrossRef]

65. Trucksess, M.W.; Weaver, C.M.; Oles, C.J.; Fry, F.S. Determination of aflatoxins B1, B2, G1, and G2 and ochratoxin A in ginseng and ginger by multitoxin immunoaffinity column cleanup and liquid chromatographic quantitation: Collaborative study. $J$. AOAC Int. 2008, 91, 511-522. [CrossRef]

66. Brera, C.; Debegnach, F.; Minardi, V.; Pannunzi, C.; Santis, B.D. Immunoaffinity column cleanup with liquid chromatography for determination of aflatoxin b1 in corn samples: Interlaboratory study. J. AOAC Int. 2007, 90, 765-772. [CrossRef]

67. Davis, J.P.; Jackson, M.D.; Leek, J.M.; Samadpour, M. Sample preparation and analytical considerations for the US aflatoxin sampling program for shelled peanuts. Peanut Sci. 2018, 45, 19-31. [CrossRef] 
68. Kang'ethe, E.K.; Gatwiri, M.; Sirma, A.J.; Ouko, E.O.; Mburugu-Mosoti, C.K.; Kitala, P.M.; Nduhiu, G.J.; Nderitu, J.G.; Mungatu, J.K.; Hietaniemi, V.; et al. Exposure of Kenyan population to aflatoxins in foods with special reference to Nandi and Makueni counties. Food Qual. Saf. 2017, 1, 131-137. [CrossRef]

69. Daniel, J.H.; Lewis, L.W.; Redwood, Y.A.; Kieszak, S.; Breiman, R.F.; Flanders, W.D.; Bell, C.; Mwihia, J.; Ogana, G.; Likimani, S.; et al. Comprehensive Assessment of Maize Aflatoxin Levels in Eastern Kenya, 2005-2007. Environ. Health Perspect. 2011, 119, 1794-1799. [CrossRef] [PubMed]

70. Food and Agriculture Organization/World Health Organization. Dietary exposure assessment of chemicals in food. In Environmental Health Criteria 240: Principles and Methods for the Risk Assessment of Chemicals in Food. A Joint Publication of the Food and Agriculture Organization of the United Nations and the World Health Organization. Chapter 6; Food and Agriculture Organization/World Health Organization: Geneva, Switzerland, 2009; pp. 1-95.

71. EURO. GEMS/Food-EURO Second Workshop on Reliable evaluation of low-level contamination of food. Report on a workshop in the Frame of GEMS/Food-EURO. In Proceedings of the Workshop in the Frame of GEMS/Food-EURO, Kulmbach, Germany, 26-27 May 1995.

72. Huong, B.T.M.; Tuyen, L.D.; Madsen, H.; Brimer, L.; Friis, H.; Dalsgaard, A. Total dietary intake and health risks associated with exposure to aflatoxin B1, ochratoxin A and fuminisins of children in Lao Cai Province, Vietnam. Toxins 2019, 11, 638. [CrossRef] [PubMed]

73. Li, P.; Ding, X.; Bai, Y.; Wu, L.; Yue, X.; Zhang, L. Risk Assessment and Prediction of Aflatoxin in Agro-Products; IntechOpen: London, UK, 2018; Chapter 18; pp. 319-334.

74. Senerwa, D.M.; Sirma, A.J.; Mtimet, N.; Kang'ethe, E.K.; Grace, D.; Lindahl, J.F. Prevalence of aflatoxin in feeds and cow milk from five counties in Kenya. Afr. J. Food, Agric. Nutr. Dev. 2016, 16, 11004-11021. [CrossRef]

75. Raad, F.; Nasreddine, L.; Hilan, C.; Bartosik, M.; Parent-Massin, D. Dietary exposure to aflatoxins, ochratoxin A and deoxynivalenol from a total diet study in an adult urban Lebanese population. Food Chem. Toxicol. 2014, 73, 35-43. [CrossRef]

76. Bellio, A.; Daniela Manila Bianchi, D.M.; Gramaglia, M.; Loria, A.; Nucera, D.; Gallina, S.; Gili, M.; Decastelli, L. Aflatoxin M1 in Cow's Milk: Method validation for milk sampled in Northern Italy. Toxins 2016, 8, 57. [CrossRef]

77. Krska, R.; Richard, J.L.; Schuhmacher, R.; Slate, A.B.; Whitaker, T.B. Romer Labs Guide to Mycotoxins, 4th ed.; Anytime Publishing Services: Leicestershire, UK, 2012.

78. Rodrigues, I.; Handl, J.; Binder, E.M. Mycotoxin occurrence in commodities, feeds and feed ingredients sourced in the Middle East and Africa. Food Addit. Contam. Part B 2011, 4, 168-179. [CrossRef]

79. AOAC. Preparation of Standards for aflatoxins: Thin-layer chromatographic-Spectrometric methods (AOAC Official Method 970.44). In Official Methods of Analysis; Cunniff, P., Ed.; Health Protection Branch, AOAC International: Ottawa, ON, Canada, 2005; pp. 43-49.

80. European Union Reference Laboratory. Guidance Document on the Estimation of LOD and LOQ for Measurements in the Field of Contaminants in Feed and Food; European Union Reference Laboratory: Lyngby, Denmark, 2016; pp. 1-52.

81. Rossi, C.N.; Takabavashi, C.R.; Ono, M.A.; Saito, G.H.; Itano, E.N.; Kawamura, O.; Hirooka, E.Y.; Ono, E.Y.S. Immunoassay based on monoclonal antibody for aflatoxin detection in poultry feed. Food Chem. 2012, 132, 2211-2216. [CrossRef]

82. Huynh, T.; Ly, C.; Knight, P.; Wolde-Mariam, W. Quantitation of aflatoxin B1 by ELISA in commodities that pose a matrix effect. In Proceedings of the AOAC 126th Annual Meeting, Las Vegas, Nevada, 30 September-3 October 2012. 